\title{
El tiempo de la danza en Guatemala
}

\author{
Amabilia Tejeda-Solórzano \\ Bailarina y coreógrafa \\ Escuela Superior de Arte \\ Universidad de San Carlos \\ Guatemala \\ Recibido: 30 de junio de 2019 \\ Aceptado: 20 de diciembre de 2019 \\ DOI: https://doi.org/10.15359/tdna.36-67.4
}

\section{Resumen}

El arte, la historia y el conocimiento son herramientas importantes para formar una mejor nación. Este artículo explora los orígenes de la danza en Guatemala, un relato que abarca desde 1860 hasta nuestros días, que destaca personalidades como bailarines y maestros con estudios y trayectorias en el extranjero. Menciona las instituciones oficiales que iniciaron el movimiento del ballet clásico, del moderno y del folclórico. Se hace referencia a la visita de espectáculos internacionales que enriquecieron la visión artística del país y descolla en importancia,

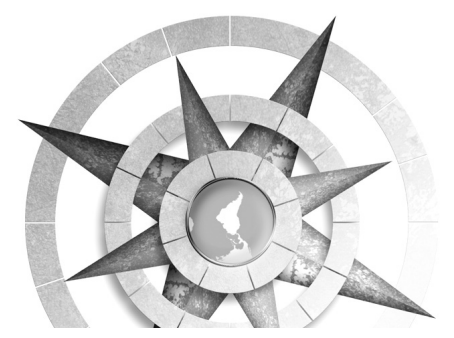

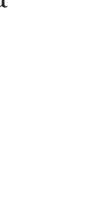

la creación de la Escuela Nacional de Danza, de agrupaciones como el Grupo de Danza de la Universidad San Carlos de Guatemala (USAC) y de numerosos estudios independientes, tanto del centro como del interior del país. El trabajo termina con algunas entrevistas efectuadas a destacadas personalidades de la danza. Las fotografías históricas, muy valiosas, enriquecen este eje discursivo. Palabras claves: Artes y danza en Guatemala, Arte en Centroamérica, Arte en América Latina

\begin{abstract}
Art, history and knowledge are important tools for building a better nation. This article explores the origins of dance in Guatemala, a story that spans from 1860 to the present day, highlighting personalities such as dancers and maestros with studies and careers abroad. It mentions the official institutions that initiated the movement of classical ballet, modern and folkloric dance. Reference is made to the visit of international shows that enriched the artistic vision of the country. The creation of the National
\end{abstract}


School of Dance, of groups such as the Dance Group of the San Carlos University of Guatemala (USAC) and of numerous independent studios, both in the center and in the interior of the country, stands out in importance. The work ends with some interviews with prominent dance personalities. The historical photographs, very valuable, enrich this discursive axis.

Keywords: Arts and Dance in Guatemala, Arts in Central America, Arts in Latin America

\section{Resumo}

A arte, a história e o conhecimento são meios importantes para a construção de uma nação melhor. Este artigo explora as origens da dança na Guatemala, uma história que se estende desde 1860 até hoje, destacando personalidades como bailarinos e maestros com estudos e carreiras no estrangeiro. Menciona as instituições oficiais que iniciaram o movimento do ballet clássico, da dança moderna e folclórica. É feita referência à visita de espectáculos internacionais que enriqueceram a visão artística do país. Destaca-se a criação da Escola Nacional de Dança, de grupos como o Grupo de Dança da Universidade de San Carlos da Guatemala (USAC) e de numerosos estúdios independentes, tanto no centro como no interior do país. $\mathrm{O}$ trabalho termina com algumas entrevistas com personalidades da dança de destaque. As fotografias históricas, muito valiosas, enriquecem este eixo discursivo.

Palavras chave: Artes e dança na Guatemala, Artes na América Central, Artes na América Latina

A mitad de siglo XIX Guatemala ya había sufrido un golpe de Estado, pérdida de territorio al norte del país, una guerra interna y otra con su vecino, El Salvador. También se había desligado de la República Centroamericana para ser una nación libre, soberana e independiente. Y desde siempre ha tenido un pueblo no conforme con su sistema de gobierno con tiranos u otras veces militares al frente.

Pero esta nación también tenía un lado humanista y artístico, Guatemala era una de las capitales principales a nivel centroamericano donde se registraban visitas de artistas extranjeros, muchas veces porque iban de pasada. Este aporte se debía a su ubicación geográfica, pues muchos artistas viajaban por tierra, haciendo giras hacia el norte o el sur. Fue esta acción una de las principales promotoras de que en Guatemala se estableciera una Compañía de Danza a nivel nacional.

Se entiende que en Guatemala había un grupo permanente de danza en la década de 1860 , perteneciente al Teatro 
Colón, todos los integrantes eran extranjeros. "Un dato que es importante resaltar es que durante el gobierno del General José Rafael Carrera y Turcios ${ }^{1}$ se prohibió que compañías teatrales y artistas nacionales actuasen en este palco, por circunstancias políticas" (Municipalidad de Guatemala, 2008). "Hubo una gran actividad escénica en dicho teatro con grupos extranjeros de ópera, zarzuela, comedia, danza y otros" (Castañeda, 2012, p. 24).

Se registró, en un material impreso de 1902, un grupo de niñas con cinco o seis años, con trajes de bailarina, coronas, alas, peinados clásicos con flor y zapatillas de media punta anudadas al tobi1lo, en las gradas del antiguo Templo de Minerva, ubicado en el Hipódromo del Norte y que fue demolido por el primer Gobierno revolucionario. Este evento se había desarrollado en una fiesta minervalia, instituida por el presidente Manuel Estrada Cabrera, quien se autodenominaba "el protector de la juventud estudiosa”. (Castañeda, 2012, p. 25).
Fotografía 1.

Teatro Carrera (más tarde rebautizado Colón, luego demolido en 1924).

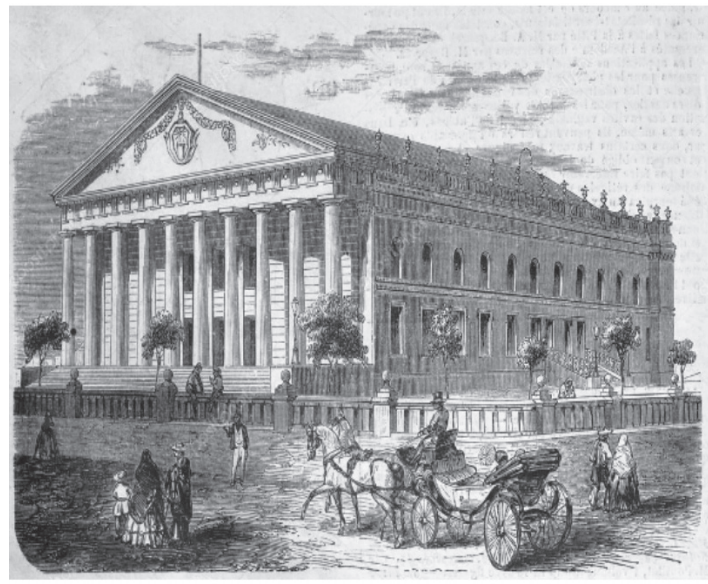

Fuente: Colección de Marzolino ${ }^{2}$

En 1917 una joven guatemalteca llamada Lochita Monzón regresó de Estados Unidos con el oficio de la danza aprendido. Ejecutaba varias danzas, pero su fuerte era de corte oriental.
1 José Rafael Carrera y Turcios (1814-1865) fue un caudillo militar guatemalteco, jefe de Estado (1844-1847) y presidente vitalicio de la República de Guatemala (1847-1848; 1851-1865). El mayor representante de la tendencia conservadora en la Centroamérica del siglo XIX Asociación de Amigos del País (2004). Diccionario histórico biográfico de Guatemala. Guatemala: Amigos del País, Fundación para la Cultura y el Desarrollo. ISBN 99922-44-01-1.
2 Dibujo de Gaildrau, después de la foto de Gibón de Fitz. Publicado en I'llustration Journal Universel, Paris, 1860. Recuperado de httpp://sp.depositphotos.com/portfolio-1733706.html 
Fotografía 2.

Lonchita Monzón.

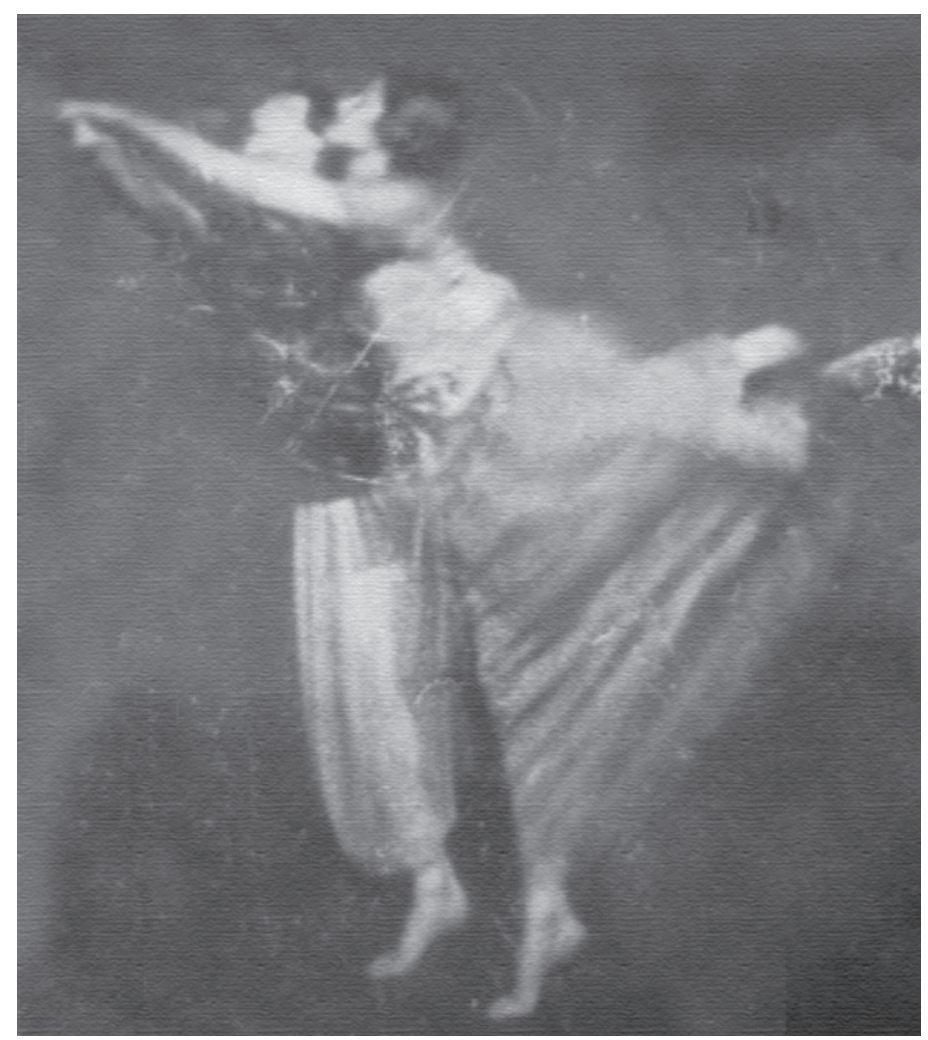

Fuente: Colección Blanca Irene Monzón .

En 1945 Juan José Arévalo Bermejo inició el primer gobierno revolucionario de Guatemala siendo el primer presidente popularmente electo en ese país, tras la Revolución de 1944. Castañeda afirma que fue el Dr. Arévalo, quien veló por hacer posible, actuaciones de profesionales en la danza como Olga Morozova, quien tenía medalla de oro europea a la mejor bailarina de la época (1934),
Jasinsky, Doukudovsky, Oleg Tupin y Keneth Mackensie. Todos estos personajes pertenecían al Original Ballet Russe del Coronel W. de Basil. ${ }^{3}$ Fue así como

3 General cosaco, empresario y director de ballet ruso, nacido en Kaunas en 1888 y muerto en París el 27 de julio de 1951, cuyo nombre original fue Vasili Grigorievich Voskresensky. Llegó a Europa en 1925 como asistente del príncipe Zereteli, encargado de la gira de L'Ópéra Russe à Paris. En enero de 1932 y como continuación de los Ballets

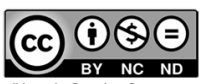

40 El tiempo de la danza en Guatemala Amabilia Tejeda- Solórzano 
presentaron en tierra guatemalteca obras como: Sílfides, Paganini, Francesca da Rímini, Carnaval, La siesta de un Fauno, Las botas de Aurora, Corillón, Sinfonía Fantástica, Ícaro, Baile de graduados, El hijo pródigo, Danubio Azul, Scheherazade, Lucha Eterna, Choreartium, Cimarosiana, Mujeres de buen humor, El gallo de Oro.

Según la edición dedicada al Ballet Guatemala, la revista Galería de la Fundación G\&T menciona que los precios de entradas para ver estos espectáculos eran de dos Quetzales en luneta y cincuenta céntimos de Quetzal, en galería. En el mes de junio del año 1946 llegan a Guatemala María Svetlova y su pareja de baile Alexis Dolinoff, ambos de la ópera Metropolitana de Nueva York (Castañeda, 2012, p. 26).

Todas estas visitas importantes fueron producto de muchas situaciones, pero ayudaron a que en Guatemala la visión cultural fuera más ambiciosa y rentable. Sin duda alguna el Dr. Arévalo, siendo la pedagogía una de sus ocupaciones, permitió que dentro de algunos institu-

Russes de Diaghilev, fundó junto a René Blum Les Ballets Russes de Monte Carlo. Tres años después, el grupo se dividió entre los seguidores de Blum, que formaron Les Ballets de Monte Carlo de René Blum, y los del Coronel de Basil, que formaron Les Ballets Russes del Coronel de Basil. En 1938, la compañía pasó a denominarse Original Ballet Russe del Coronel de Basil. El grupo se instaló en Sudamérica, realizó giras por América y regresó a Europa tras la Segunda Guerra Mundial. En 1948 se presentó en distintas capitales españolas, y ese mismo año se disolvió. Muchos integrantes regresaron a países americanos (Paris y Javier, 2011). tos de educación básica se impartieran clases de Danza para que la educación fuese más humanista.

En ese entonces todo el pueblo guatemalteco estaba emocionado y las jovencitas deseosas de poder llegar a ser como estas bellas, agraciadas y etéreas bailarinas, también algunos jóvenes se sumaron a las clases. Fue así como Consuelo Polantinos, Fabiola Perdomo, Thelma Orellana, Judith Alvarado, María Rojas y Alberto Navas fueron los primeros en destacar en el oficio; varios de ellos se entrenaron con los grandes profesionales que llegaban a la capital. Fue así como se organizó el primer grupo de posibles candidatos con el objetivo de crear la flexibilidad necesaria para ejecutar cualquier forma de danza; fueron entrenados bajo la tutela de Mme. Marcelle Bonge. Ella había emigrado del sur, desde Bogotá, Colombia. A finales del año 1946 llega a Guatemala el maestro formador de Marcelle, Kiril Pikieris. Él prepara un grupo de jóvenes al cual le llama Caravana, que hacen su primera presentación en julio de 1947. Existen datos en el periódico "El imparcial" donde fue publicada una favorable crítica y el repertorio de las piezas que fueron bailadas: Vals lento de débiles, Tarantela de Rossini, Cuevas gitanas de Lima, Romanza de Rubinstein, Amor campesino de Cortés, Cuadro indigena de Leopoldo Ramírez, Vals triste de 
Sibelius, Preludio No. 24 de Chopin, Campesinas de José de Báez, Bailare ruso de Tchaikovski, Danza Maya Chortí de Leopoldo Ramírez.

El 28 de enero del año 1948 aparece en Nuestro Diario ${ }^{4}$ una carta de don Oscar Vargas Romero para el director de dicho periódico, señor Baltasar Morales. En ella explica don Oscar, en ese entonces jefe del Departamento de Educación y Estética, que el alcalde de Nueva York y el presidente del Comité de Festejos del Gran Jubileo de Oro de esa ciudad habían extendido una invitación a Guatemala para que en el Gran Festival de Danzas fuera representado el país por un grupo de danza clásico o de folclor (Castañeda, 2012). Fue entonces cuando Marcelle Bonge y su esposo Jean Devaux gestionan un conjunto permanente del Estado, con trámites legales en el Departamento de Educación Estética; con el objetivo de formar un Ballet Nacional de Danza Contemporánea y Folclórica. Reúnen un buen número de bailarines y aspirantes para ser entrenados durante diez meses, incluyendo montajes. Se presentan el 16 de julio de 1948 en el teatro Capítol, es entonces la primera función del Ballet Guatemala.

4 La primera edición de Nuestro Diario salió a las calles el 16 de enero de 1998, dirigido a la población guatemalteca, a más de 316, 648 familias; sus lectores son hombres y mujeres entre los 13 y los 60 años. httpp://www.nuestrodiario.com/

Fuente: Colección Roberto Castañeda

Fotografía 3.
me. Marcelle Bonge.

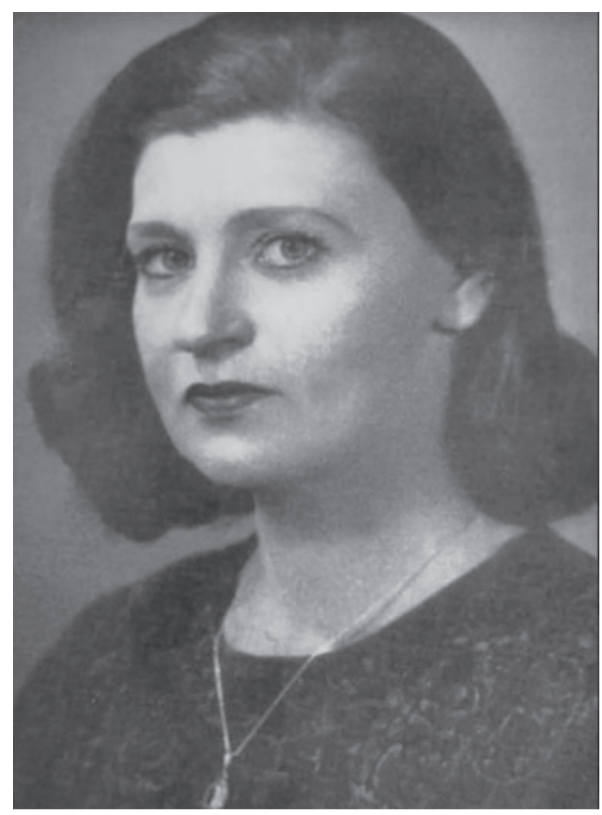


Fotografía 4.

Marcelle Bonge y Jean Devaux.

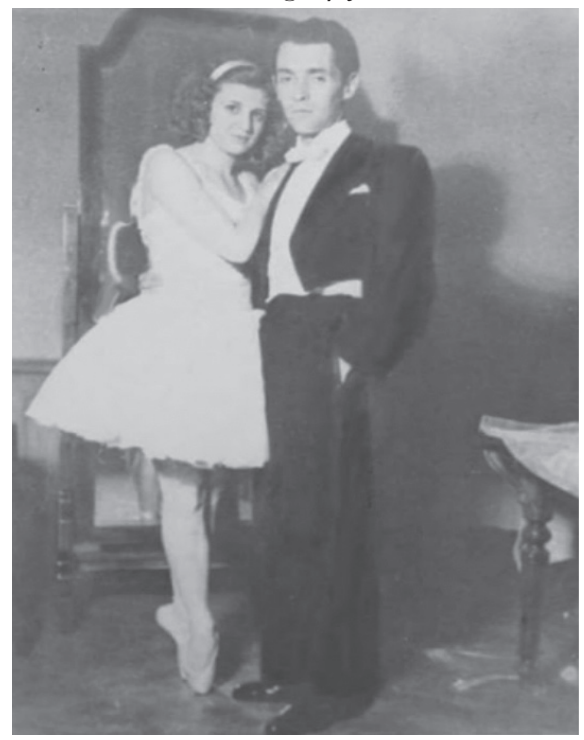

Fuente: Colección Richard Devaux Bonge

En ese mismo año, en octubre, hay una visita grata de un país hermano centroamericano. El Ballet Infantil de Costa Rica, miembros de la Escuela de Danza Margarita Esquivel, hacen una presentación dirigida por Olga Franco Spinach (issuu, 2012).

A partir de este año, 1948, el Ballet Guatemala es el grupo embajador de la cultura y el arte en el país. Reciben maestros extranjeros para que puedan compartir conocimientos con este grupo dispuesto a formarse como profesional. Más adelante hay un intercambio de bailarines y maestros. 
Fotografía 5.

Fundadores del Ballet Guatemala. Antigua Guatemala, 1948.

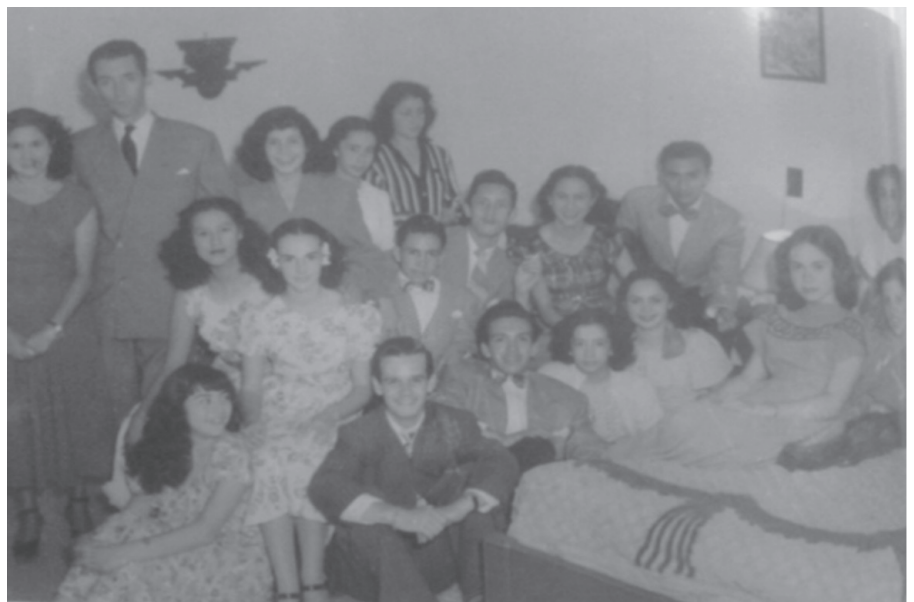

Fuente Colección: Roberto Castañeda

Fotografía 6.

Clase de Danza en el Instituto Belén, enero de 1948.

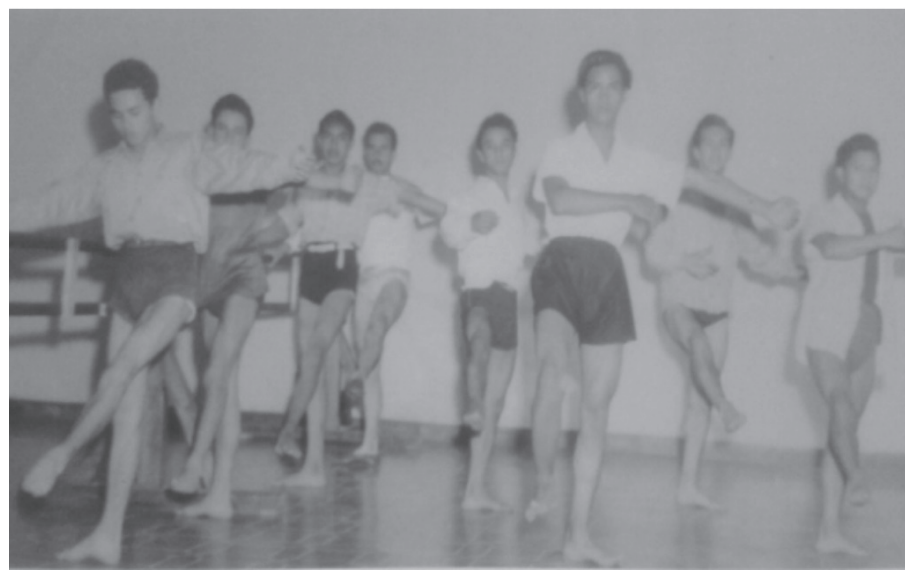

Fuente: Colección Roberto Castañeda

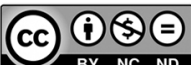




\section{Fotografía 7.}

Izquierda: Palace. Derecha: Capítol. Antiguos edificios de los teatros más importantes de Guatemala en la década de los años cuarenta.

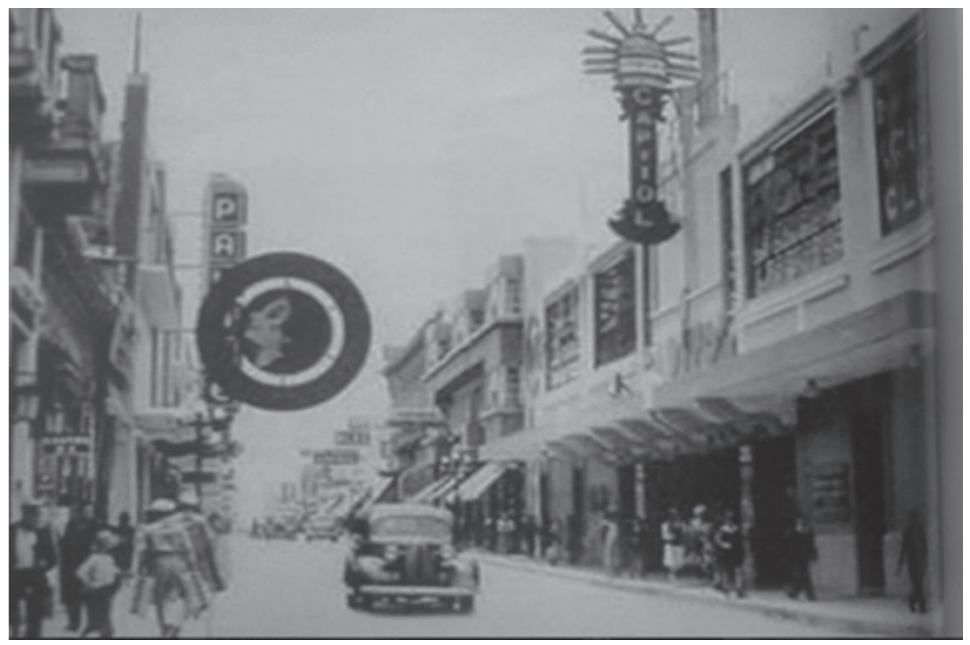

Fuente: Colección César Urrutia (2011)

\section{Fotografía 8.}

Vals de las Flores, 1948 Ballet Guatemala en el Palacio Nacional.

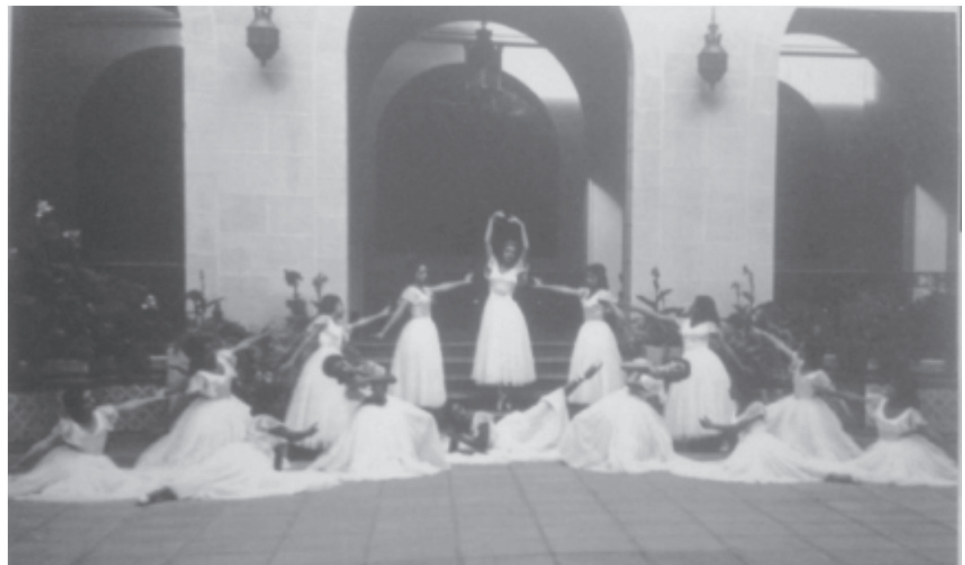

Fuente: Colección Roberto Castañeda

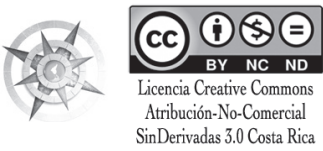




\section{Fotografía 9.}

Estampa guatemalteca, 1949. Sonia Villalta, Manuel Ocampo, Otto Paul Ricart, Zoila Perdomo, Roberto Castañeda, Mirna Farres, Carlos Mejicanos, Edmee Oliva, y Thelma Ossendorf y Gloria Zirion.

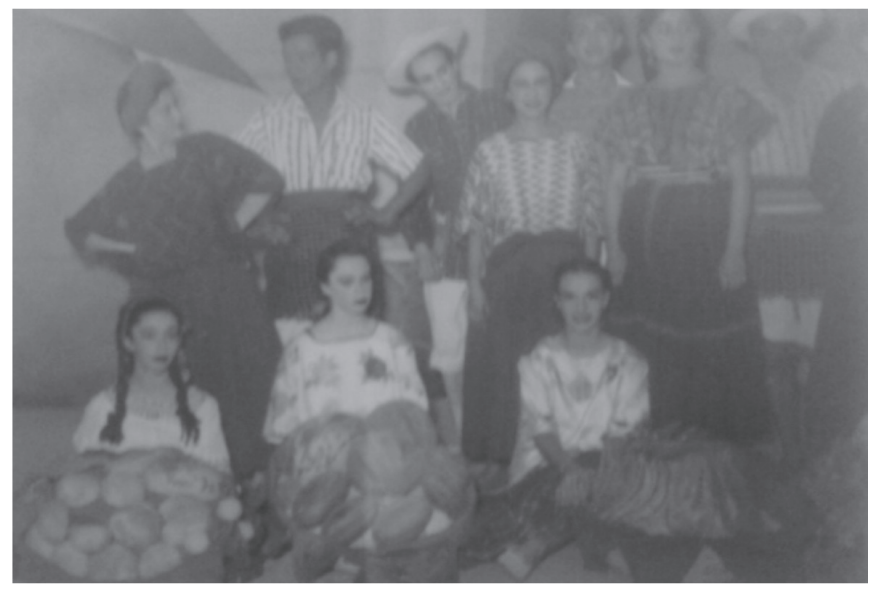

Fotografía 10.

Principe Igor, 1949.

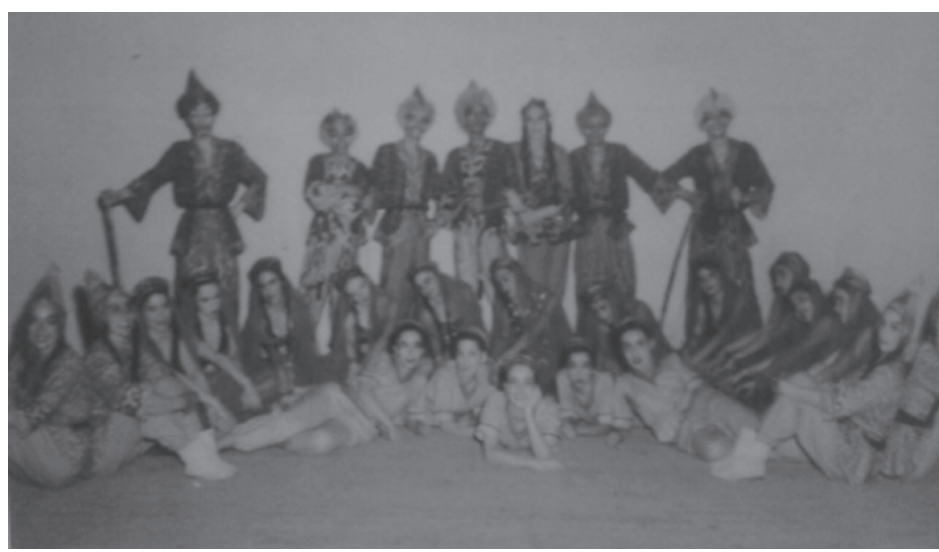

Fuente: Colección Roberto Castañeda

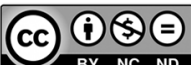




\section{Fotografía 11.}

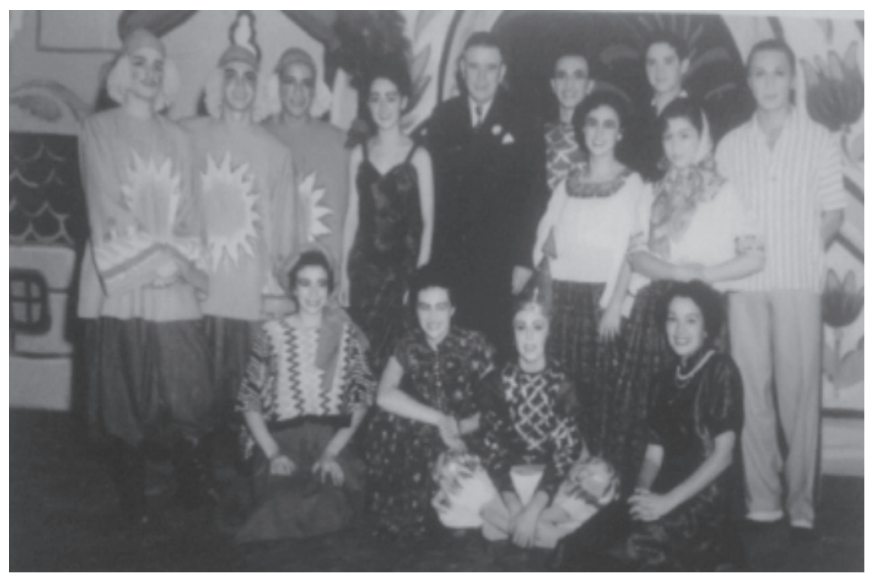

Fuente: Colección Roberto Castañeda

Fotografía 12.

Leonide Katchourowsky.

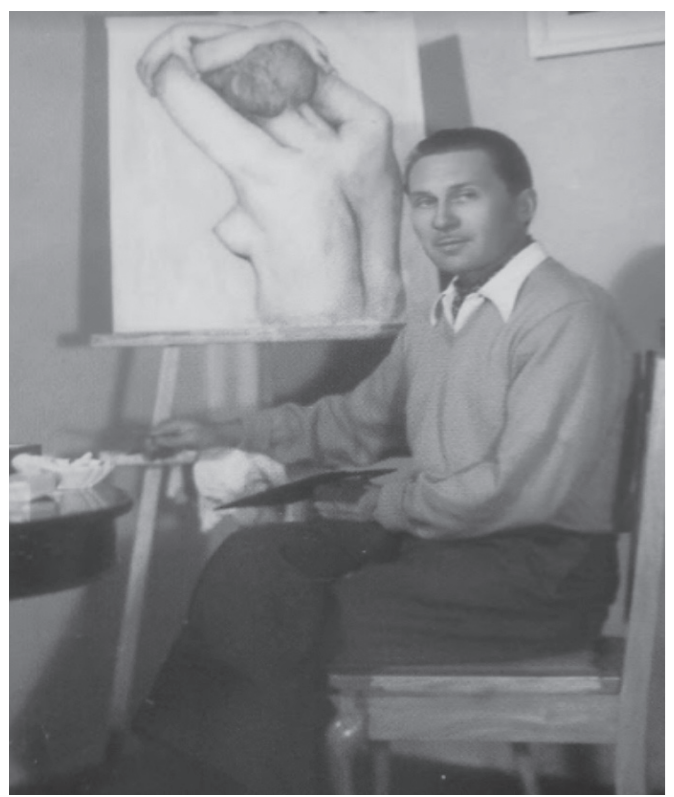

Fuente: Colección Roberto Castañeda

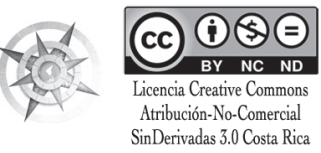




\section{Fotografía 13.}

Bailarines Sonia Villata, Julia Vela, Christa Mertins, Manuel Ocampo y José Limón, 1958.

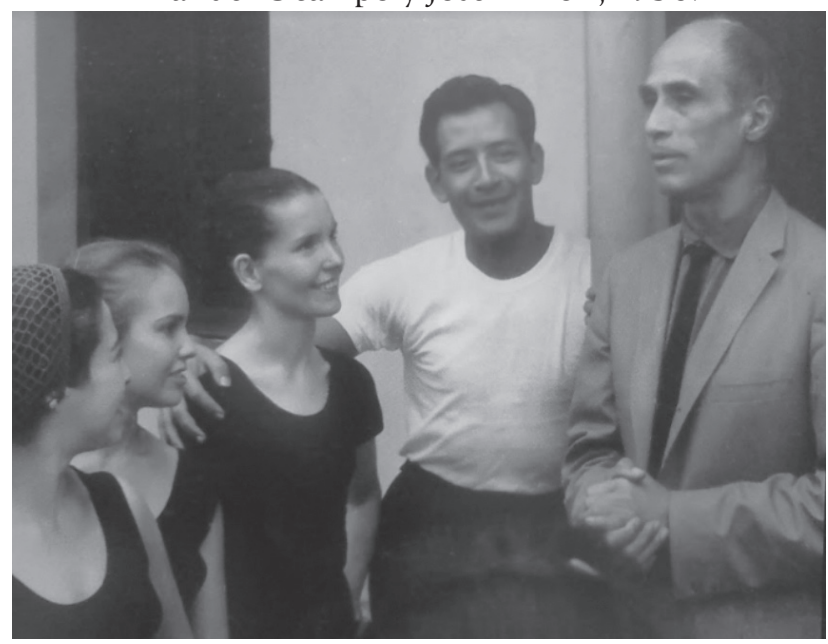

Fuente: Colección Castañeda

Fotografía 14.

Bailarines Miriam Morales, Antonio Crespo y Manuel Ocampo en Pájaro Blanco. Música de Jorge Sarmientos. Coreografía de Denis Carey1957.

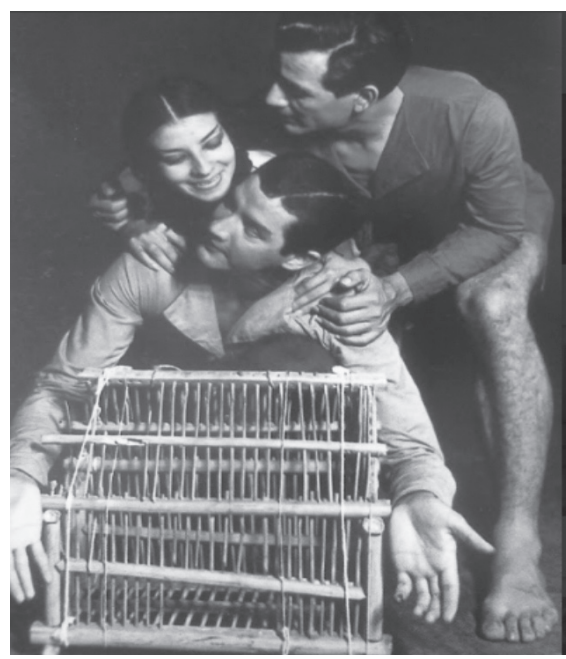

Fuente: Colección Castañeda

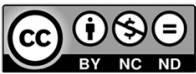




\section{Fotografía 15.}

Don Juan, 1959. Roberto Castañeda, Marcelle Bonge y Manuel Ocampo.

Colección Castañeda

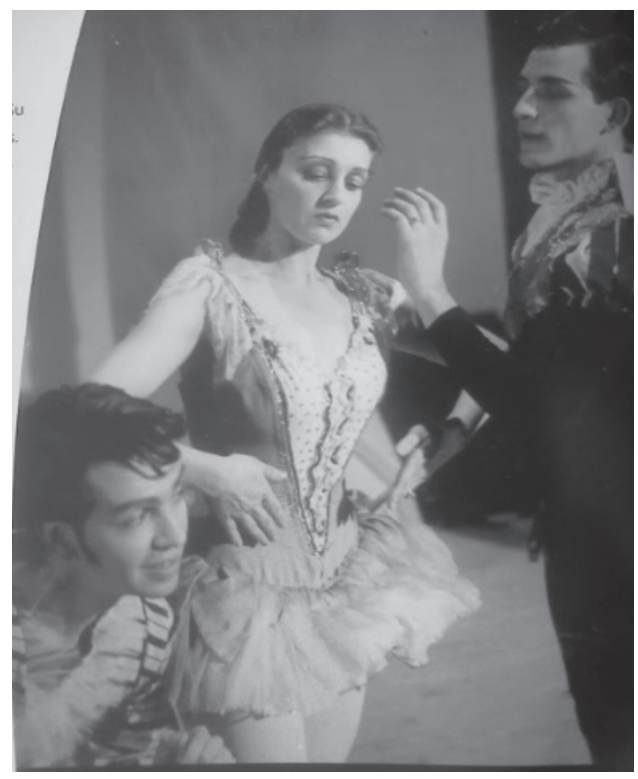

El Ballet Guatemala siguió teniendo éxito por muchos años más, presentando obras de maestros nacionales e internacionales. También el grupo fue cambiando de directores.

\section{Directores Jel Ballet Guatemala}

- $\quad$ Marcelle Bonge, 1948-1949

- Leonid Kachurovsky, 1949-1954

- A mediados de 1954 la contrarrevolución cierra el Ballet Guatemala.

- Denis Carey (apertura), 1955-1957

- Fabiola Perdomo, 1959

- Joop van Allen, 1960-1961

- Antonio Crespo, Época de Oro del
Ballet Guatemala, 1962-1974

- Brydon Paige (director huésped), 1970-1972

- Christa Mertins, 1978-1979

- Sonia Juárez, 1980-1985

- Manuel Ocampo, 1982

- Brenda Arévalo, 1985-1987

- Sonia Juárez, 1981-1987

- Carlos Marroquín, 1991-1998

- Eddy Vielman, 1998

- Amalí Selva, 1998-2009

- Sonia Marcos, 2009-2010

- Lissette Aguillar, 2010

- Sonia Marcos (actualmente) 
ISSN 0259-2339 - EISSN 2215-5449

Fotografía 16.

Época de Oro del Ballet Guatemala Antonio Crespo.Director, 1962-1974.

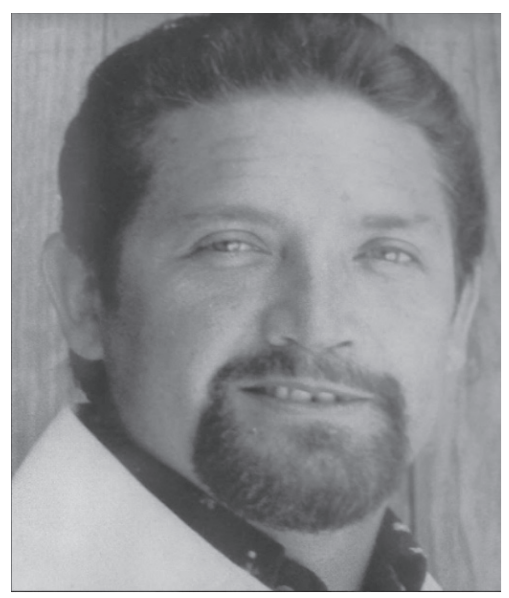

Fotografía 17

Denis Carey. Director, 1958-1959.

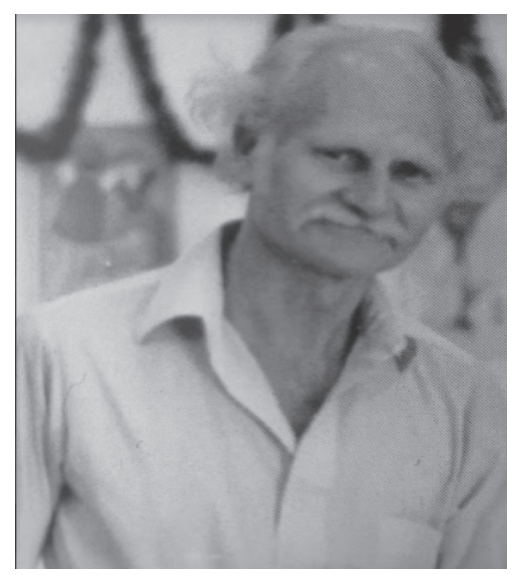


Fotografía 18.

Brydon Paige. Director huésped 1970-1972.

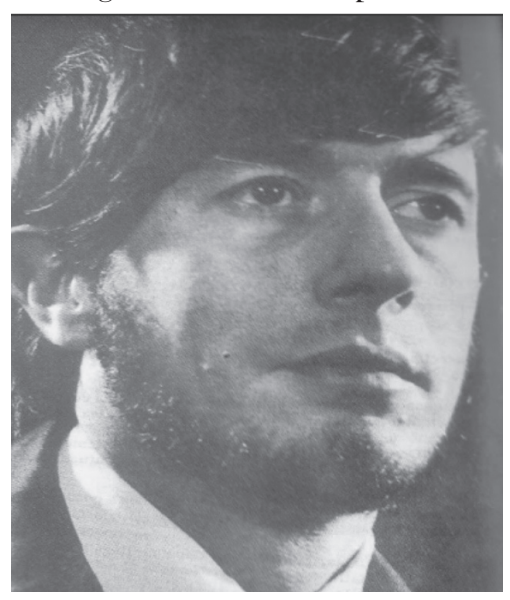

Fotografía 19.

Christa Mertins. Director: 1958-1959

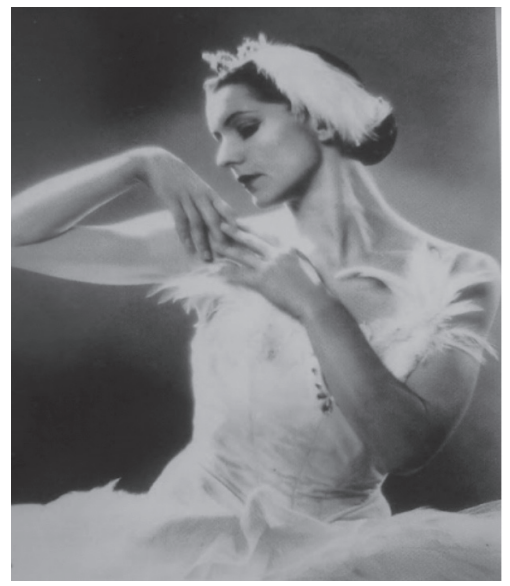


La compañía oficial seguía creciendo con buenos ánimos. Fue un éxito a nivel centroamericano. Los años siguieron pasando y los bailarines seguían con entusiasmo entrenando y presentando propuestas nuevas de coreógrafos nacionales e internacionales.

Una de las épocas más importantes para este grupo transcurrió bajo la dirección del bailarín, coreógrafo y maestro guatemalteco Antonio Crespo (1962-1977), el Ballet Guatemala logra su mejor momento y se le conoce como Época de Oro. Es aquí donde el grupo hace giras a nivel internacional e intercambio y profesionalización de bailarines y bailarinas nacionales fuera del país. A esto contribuyó grandemente Christa Mertins, quien fue parte de Les Grands Ballets Canadiens, y a cuya escuela acudieron varias de las nuevas generaciones de la danza de esa época (Mertins, 2012).

Es trascendental señalar que, por mucho tiempo, hubo personas que hicieron que muchos logros fueran posibles, porque apoyaban la ideología de la cultura y el arte en el país, estas personas tenían puestos importantes dentro de la Administración, pues poco a poco los Gobiernos fueron perdiendo el interés por esta institución. Eunice Lima era la directora general de Bellas Artes, impulsó de gran manera a todas las artes nacionales, pues el Estado había limitado los recursos asignados para dicha dependencia (Mertins, 2012).
Los Gobiernos venideros y los altos mandatarios cortaron cada vez más el presupuesto para la Compañía del $\mathrm{Ba}$ llet Guatemala. Y los integrantes bailarines de la llamada Época de Oro se rehusaban a dejar sus puestos para nuevas generaciones. Entonces, esto dejó visiblemente expuesto cómo el nivel técnico de la Compañía fue deteriorándose con el tiempo. Uno de los grandes maestros y coreógrafos extranjeros, se expresó así en un periódico local, diario El Gráfico, abril 1979: "En primer lugar la inoperante organización del ballet. Es una burocracia en la que tiene uno que resignar su arte a una serie de factores". Luego agregó: "Me enfrenté a un elenco incompleto...les sobra elemento que no hace nada. Se encuentra usted con bailarinas en cinta, o con tres o cuatro años de no ensayar pero que sí cobran sus sueldos. Esto naturalmente, cierra la oportunidad a bailarines jóvenes y con talento, que sí pueden trabajar, es decepcionante" (Mertins, 2012, p. 17). 
Fotografía 20.

Paul Mejía.

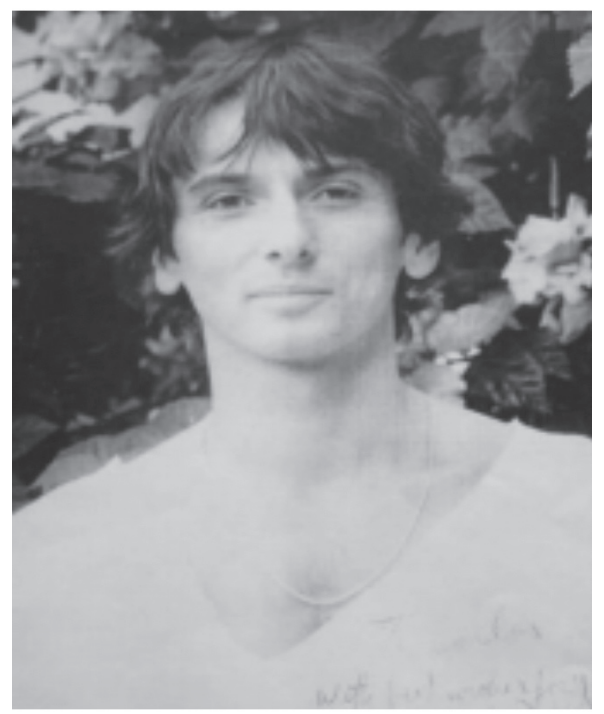

Fuente: Colección: Salomé Salazar

En una entrevista importante que realiza Lizette Mertins a Eunice Lima momentos políticos en los que la danza (ambas bailarinas y coreógrafas guatese diluía en el olvido. Eunice Lima semaltecas) en el 2009, menciona que el apoyo institucional se redujo significativamente, puesto que el arte no era ya un asunto primordial en la materia de Estado, los artistas sufrían las consecuencias del conflicto armado que estaba alcanzando su punto álgido y de ñaló también: "Los movimientos sindicalistas no ayudaron a que el gobierno prestara más atención al gremio artístico". (Lima, 2009) 
Fotografía 21.

Lizette Mertins, 2014.Teatro de Cámara "Hugo Carrillo".

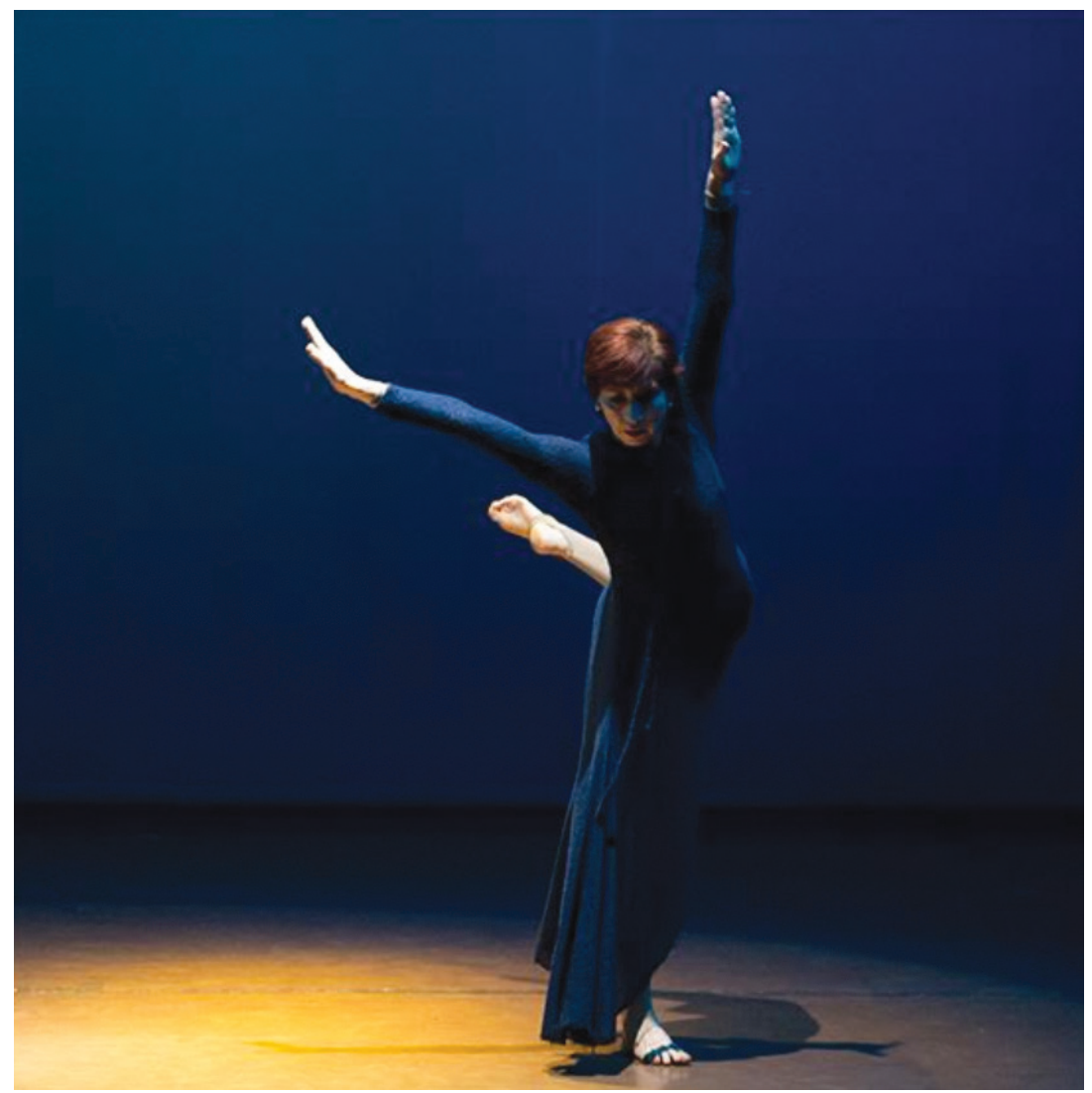

Fuente: Fotografía por Mario Cabrera Colección MUSAD

Mertins menciona en su investigación que, con el paso del tiempo, uno de los fuertes problemas que fue debilitando a este grupo era que no todos los bailarines se encontraban en el mismo nivel técnico y, por tradición, dentro del Ballet Guatemala se habían manejado diferentes jerarquías en sus filas; sin embargo, uno de los principales síntomas que sufría la Compañía era el envejecimiento de sus integrantes. Es así como se inicia un movimiento de presión para que los bailarines principales dejaran sus

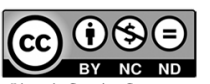

54 El tiempo de la danza en Guatemala Amabilia Tejeda- Solórzano 
cargos a las nuevas generaciones que estaban integrándose a las filas del grupo. También se trata de enviar a un grupo de bailarines experimentados a otras dependencias dentro de la Dirección de Cultura y Bellas Artes, esto naturalmente provocó una fuerte resistencia dentro del grupo afectado. A nivel general, el Gobierno de Romeo Lucas García ${ }^{5}$ no apoyaba a ninguno de los grupos artísticos y se perdió la voluntad política para llevar a cabo los cambios necesarios.

En el período de 1980 a 1985 Sonia Juárez, una de las destacadas bailarinas guatemaltecas Época de Oro del Ballet Guatemala, es nombrada directora de la Compañía. Justo en estos años el país estaba padeciendo las serias consecuencias del enfrentamiento entre militares y guerrilleros. Describe Mertins en su investigación:

El 31 de enero de 1980 un grupo de manifestantes en pro del respeto y el cese de hostilidades que se estaban suscitando en varias comunidades del altiplano indígena, tomaron la sede de la Em-

5 Fernando Romeo Lucas García (1924-2006) fue un terrateniente, militar y político guatemalteco. Se desempeñó como ministro de la Defensa, como coordinador del proyecto de la Franja Transversal del Norte y como presidente de Guatemala del 1 de julio de 1978 al 23 de marzo de 1982, cuando fue derrocado por el golpe de Estado que llevó al poder al general Efraín Ríos Montt. Después se exilió en Venezuela, donde falleció el 27 de mayo (Elías, 2006). bajada de España ${ }^{6}$ en la ciudad de Guatemala. Las fuerzas de seguridad de la época capturaron el edificio, quemándolo, dando como resultado trágico la muerte de 37 personas. Como consecuencia de este hecho, el gobierno de España rompió relaciones diplomáticas con Guatemala, las cuales fueron reanudadas en 1984. Las desapariciones forzadas y asesinatos de líderes estudiantiles y sindicalistas iban en aumento; así como el ataque a comunidades indefensas de campesinos indígenas en varios departamentos del país, principalmente en Quiché, Huehuetenango, Baja Verapaz y Chimaltenango. (Mertins, 2012, pág. 20)

El país entero estaba en una situación de crisis la corrupción que había en el Estado y la falta de atención de las instituciones dedicadas al arte tuvieron consecuencias y fueron sumándose más problemas. Cuando se da el conflicto armado interno, muchos artistas se vieron obligados al exilio, esto también afectó la continuidad del

6 La quema de la Embajada de España, en la que fallecieron cremadas treinta y siete personas, ocurrió durante el régimen militarista de Romeo Lucas (1978-82). Dicha tragedia se produjo el 31 de enero de 1980 (hace treinta y siete años), a raíz de la toma de dicha sede diplomática por subversivos, que portaban bombas incendiarias de fabricación casera, quienes retuvieron a varias personas que se hallaban en su interior, incluyendo al jefe de la misión diplomática Máximo Cajal y López (El Periódico, 2017). 
grupo. El gremio de los actores fue el más afectado, muchas de las obras de teatro eran con fines de protesta ante la inconformidad que se vivía en ese entonces. Hubo muchos casos de personajes desaparecidos y asesinados. ${ }^{7}$

Uno de los documentos donde se expresa la guerra interna que vivía Guatemala en ese entonces desde el punto de vista de los artistas, en este caso visuales. Es el "Manifiesto Vértebra" (Ordóñez, 2008).
7 Esta inconformidad comenzó desde la llamada Revolución de octubre 1944, pero el levantamiento armado se llevó a cabo durante la década de los años setenta, con la formación de pequeñas guerrillas. El militar al mando del sistema se vio en la necesidad de golpear las bases campesinas que sustentaban la fuerza guerrillera para ganar este conflicto. La represión que vivía el pueblo era el común denominador en las instituciones y organizaciones, dentro de ellas los medios de comunicación masivos. Puesto que su papel de informar al pueblo de lo que sucedía en el interior fue callado muchas veces, jugando así un papel bastante conservador y cobrando víctimas, especialmente periodistas reporteros, esto provocó autocensura frente a la apariencia político-militar. "Se dice que el Conflicto Armado interno guatemalteco duró 36 años, dejó una cauda de cien mil muertos, un millón de desplazados, miles de torturados y desaparecidos" (Veliz, 2012, )
Fotografía 22.

Miembros del grupo Vértebra: Elmer

René Rojas (izquierda), Marco Augusto

$$
\text { Quiroa (centro) y }
$$

Roberto Cabrera (derecha).

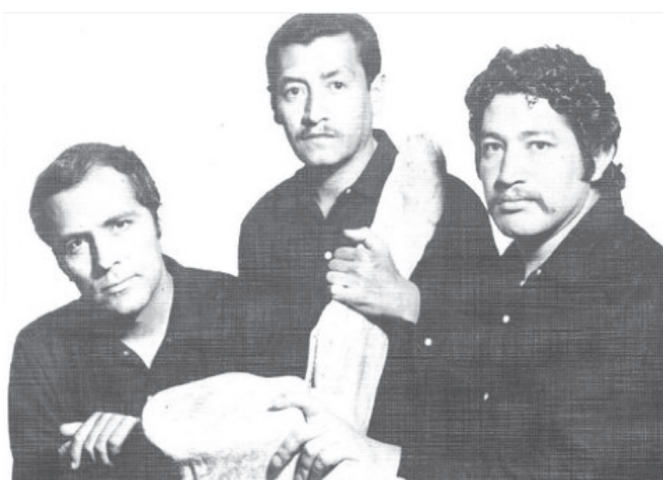

Fuente: Colección Universidad Francisco Marroquín.

\section{Luego se creó el Ministerio de Cultura y} Deportes,${ }^{8}$ el cual fue un duro retroceso para el arte nacional, y en especial para la danza. Dicho Ministerio no tenía el concepto de lo que implicaba el arte de la danza y lo útil que podría haber sido para el Gobierno. Los grupos artísticos se fueron quedando solos, al Gobierno no le interesó este tipo de

8 El Ministerio de Cultura y Deportes fue fundado en 1986, siendo su fundador y primer ministro, el reconocido artista guatemalteco Elmar Rojas, durante la Administración del entonces elegido presidente Vinicio Cerezo. La misión de la creación del ministerio fue el fortalecimiento de la identidad de Guatemala, fomentando la policultura del país, mediante la protección, promoción y divulgación de valores artísticos, culturales y sociales de Guatemala (Museos Centroamericanos, 2012). 
manifestaciones y a la fecha el gremio artístico se pregunta por la utilidad del Ministerio de Cultura y Deportes (Mertins, 2012).

Al respecto comentó la fallecida exministra de Cultura y Deportes, Eunice Lima:

Era Mejía Víctores quien estaba gobernando cuando se hizo la Asamblea Nacional Constituyente, yo formé parte de esa Asamblea, yo era Constituyente y llegaban todos los artistas a apoyarme porque nosotros queríamos que se volviera el Ministerio; que la cultura tuviera un Ministerio para la cultura, porque a través de un Ministerio se podían lograr muchas cosas eso pensé yo, cuando estuve impulsando esa idea y la apoyaba, después ven ustedes llegar al Ministerio que era Cultura y Deportes y la cólera que me daba era que toda la plata se iba para deportes (Lima, 2009).

Vinieron muchos períodos más de directores, pero el ballet venía en decadencia. Uno de los directores que es bueno mencionar después de todos los problemas que enfrentó la Compañía, como recorte de presupuesto, falta de atención en procesos de renovación de planillas, conflictos de guerra, abandono de maestros reconocidos y profesionales, destrucción de la
Dirección de Bellas Artes, es el exbailarín Carlos Marroquín, 1991-1998, quien dirigió esta institución. Él hace una invitación de nuevo a los bailarines fundadores para que realicen nuevos montajes en los viejos repertorios. Hace posible que de nuevo puedan viajar a los países de Centroamérica y México (Mertins, 2012).

En estas fechas los conflictos de guerra interna ya estaban cesando un poco y en el año 98 se firma la paz (Hemeroteca Prensa Libre, 2016). ${ }^{9}$

9 El domingo 29 de diciembre de 1996, el Gobierno de Guatemala y la Unidad Revolucionaria Nacional Guatemalteca suscribieron el Acuerdo de $\mathrm{Paz}$ firme y duradera, poniendo fin a un conflicto armado de treinta y seis años (Hemeroteca Prensa Libre, 2016). 
Fotografía 23.

Ballet Guatemala en Los galanes de Rosita, 1996.

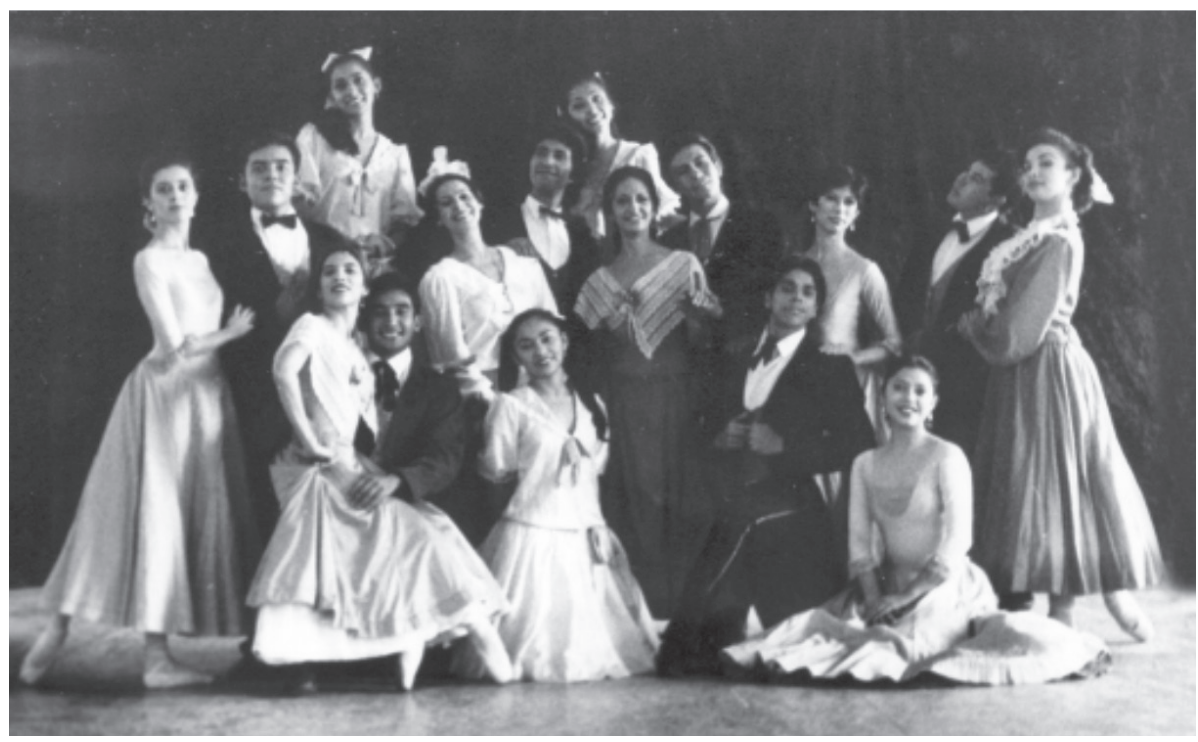

Fuente: Colección Ballet Nacional de Guatemala

El Ballet Guatemala siguió sus labores y los directores fueron cambiando, haciendo aportes y siempre tratando de que el grupo no se desintegrara por peleas internas y mala comunicación. Sin embargo, hubo otros bailarines que tuvieron la visión de formar otra compañía que no representara solo ballet clásico. Fue así como se formó el Ballet Moderno y Folclórico.

\section{Ballet Moderno y Folclórico}

Surgido a finales de 1964, este conjunto de danza tenía como fin primordial proyectar la identidad nacional guate- malteca por medio de la creación de obras integradas con valores y temas nacionales, así como el cultivo de la danza contemporánea en sus diferentes modalidades y proyectarlas organizadamente, dentro y fuera del país. Este grupo surge por la inquietud de Judith Armas, a la que pronto se añadirían Julia Vela e Iris Álvarez. Se consolidó con la llegada a sus filas de varios bailarines y bailarinas del Ballet Guatemala, entre ellos Haydée Vásquez e Hipólito Chang, que, deseosos de incursionar en otras ramas de la danza, se aventuran en un nuevo proyecto (Mertins, 2012).

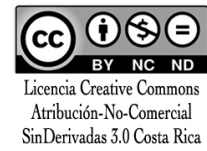


Por suerte, esta agrupación se formó bajo la Dirección de Bellas Artes. Para la dirección y formación de este nuevo proyecto, se trajeron en un primer mo- mento maestros extranjeros, entre ellos Vol Quitzow, Farnesio de Bernal y Guillermo Keys Arenas (Mertins, 2012).

\section{Fotografía 24.}

Estreno mundial de El Paabanc, Arequipa (Perú), 1972.

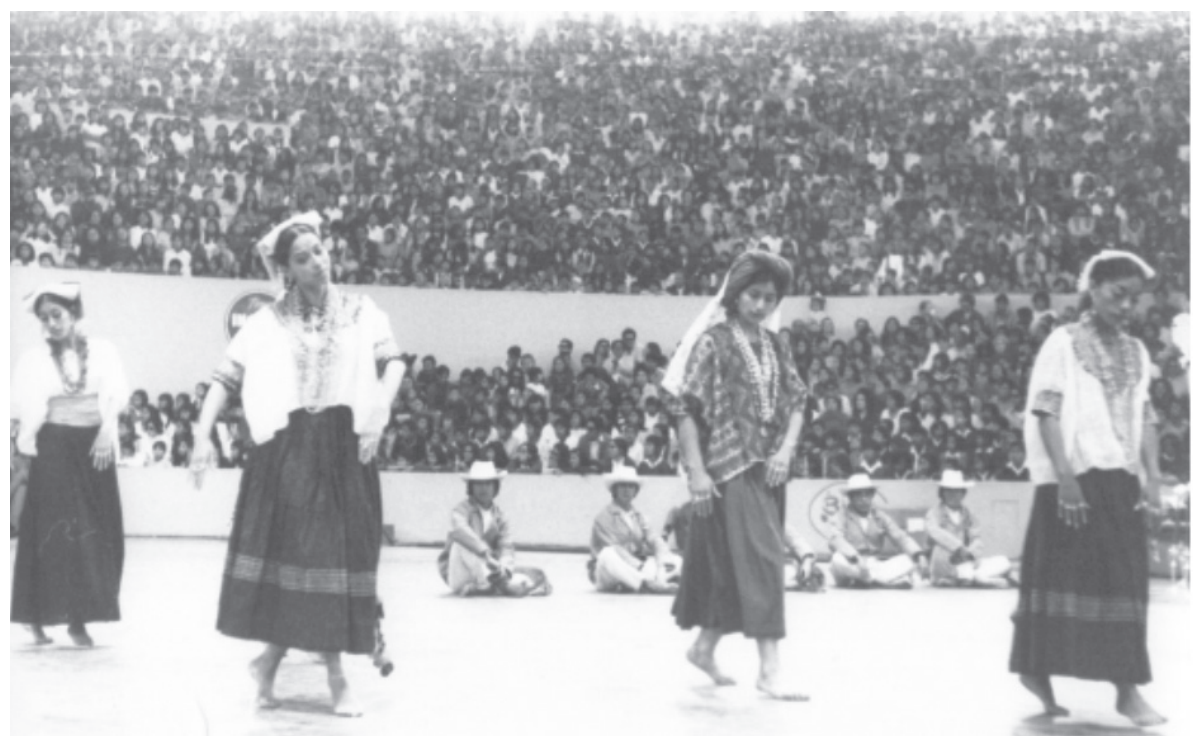

Fuente: Colección Haydée Vásquez 


\section{Fotografía 25.}

Erwin Schumann y Julia Vela, en Tormenta de cristal.

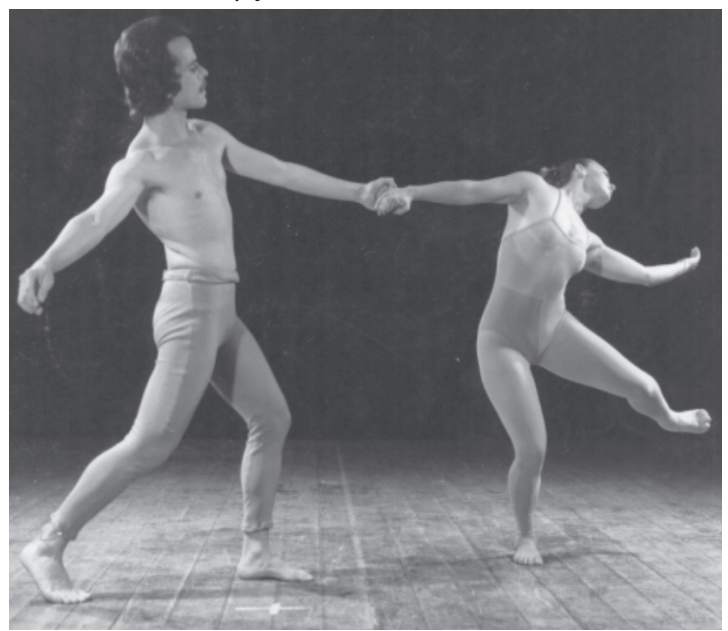

Fuente: Colección Julia Vela

\section{Fotografía 26.}

En el río, coreografía de Farnesio de Bernal.

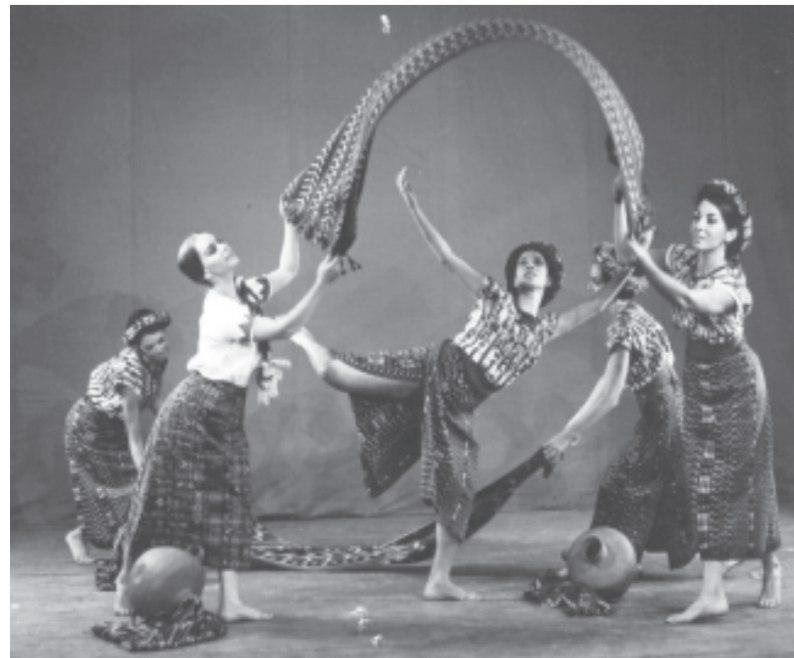

Fuente: Colección Haydée Vásquez

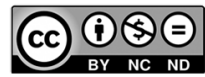


Se realizaron diferentes giras a diferentes estados de los Estados Unidos, México y otros lugares, los montajes en su Administración no tienen el brillo que tuvieron los que se dieron en la Administración de Julia Vela.

La primera presentación que realizó el Ballet Moderno y Folclórico bajo la dirección de Miguel Cuevas fue durante la temporada escolar realizada en marzo de 1980. En esa oportunidad se presentó Los aparecidos, al respecto una nota periodística de la época refiere: "La adaptación teatral de las leyendas de Guatemala se debe a La danza teatral en Guatemala (1978-2010) preocupación de la escritora guatemalteca; jefe del departamento de Letras de la Dirección General de Bellas Artes; Delia Quiñónez de Tock; quien se basó fundamentalmente en la obra: "Leyendas y casos de la Tradición de la ciudad de Guatemala' del licenciado Celso A. Lara" (Mertins, 2012, p 50).

\section{Fotografía 27.}

"Los rezadores de la noche", pieza de la obra Los aparecidos.

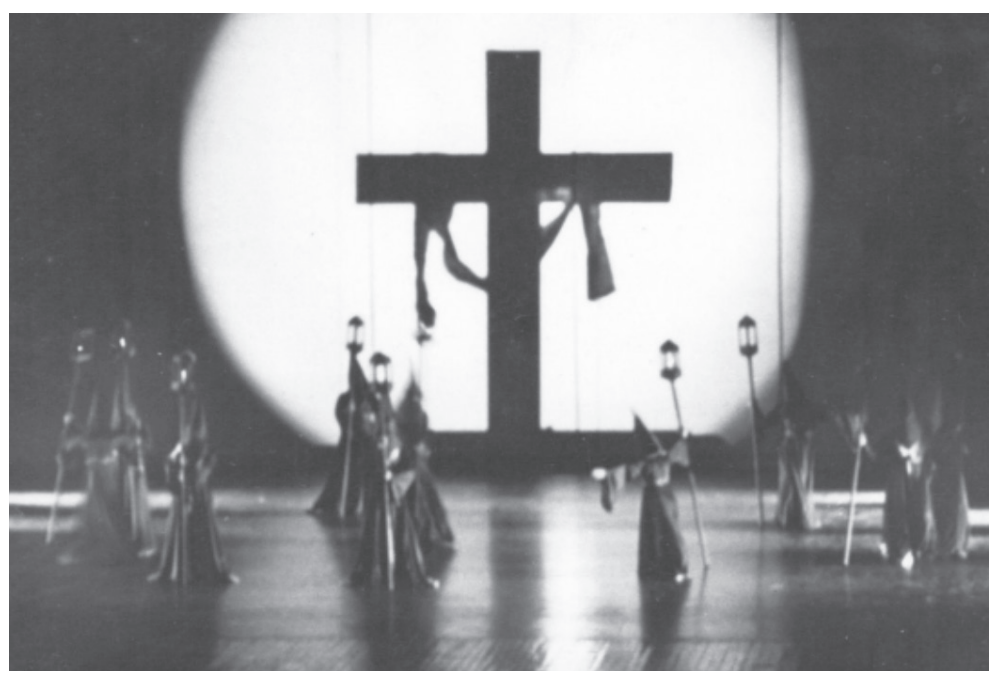

Fuente: Colección Julia Vela. 


\section{Fotografía 28.}

"Los rezadores de la noche", pieza de la obra Los aparecidos.

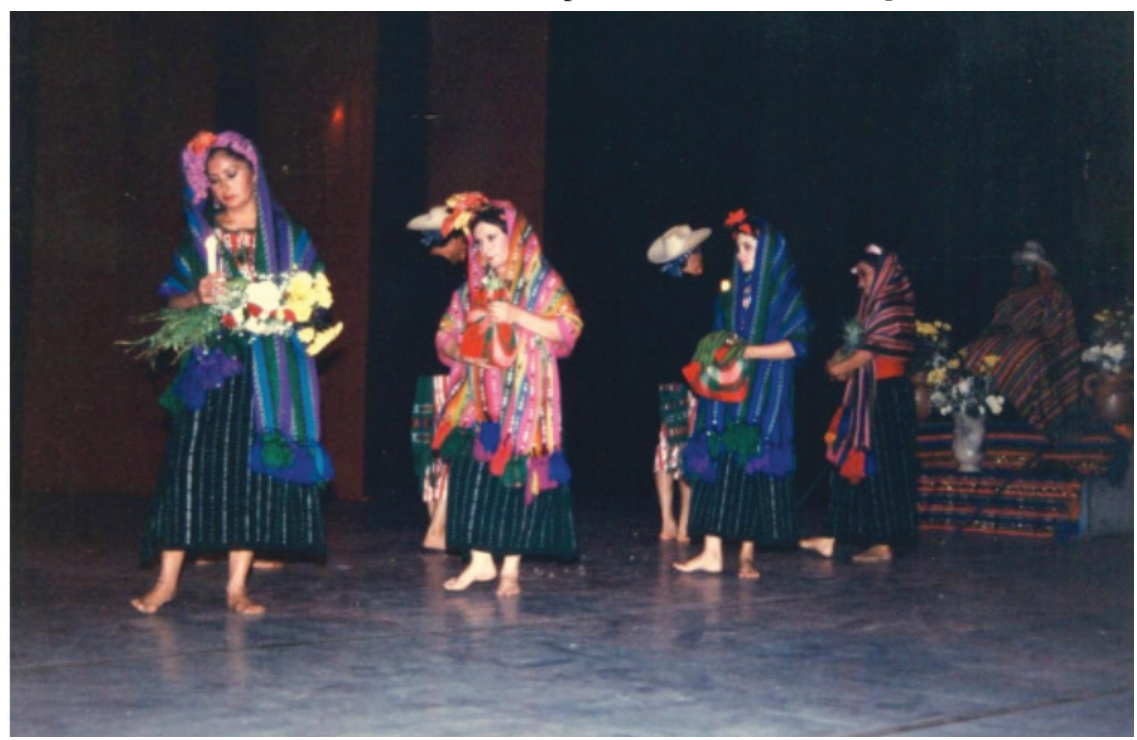

Fuente: Colección Julia Vela

De igual manera, esta institución también fue cambiando de directores; las giras internacionales fueron más frecuentes en el período de 1992 al 2010, cuando la directora era Lucía Armas. Ella hizo posible la venida de un maestro mexicano al Ballet Moderno y Folclórico. En la entrevista realizada por Mertins, Lucía Armas dice: "La primera gira que se hizo durante este período fue a Bélgica a un festival de danza folclórica, la situación económica del grupo era bastante difícil, así como en todo el país, pero esas invitaciones en las que se les ofrecía el hospedaje y la alimentación era cosa de aprovechar, por lo que los boletos eran una deuda que ellos adquirían personalmente". (Armas, 2012) 
Fotografía 29.

Lucía Armas.

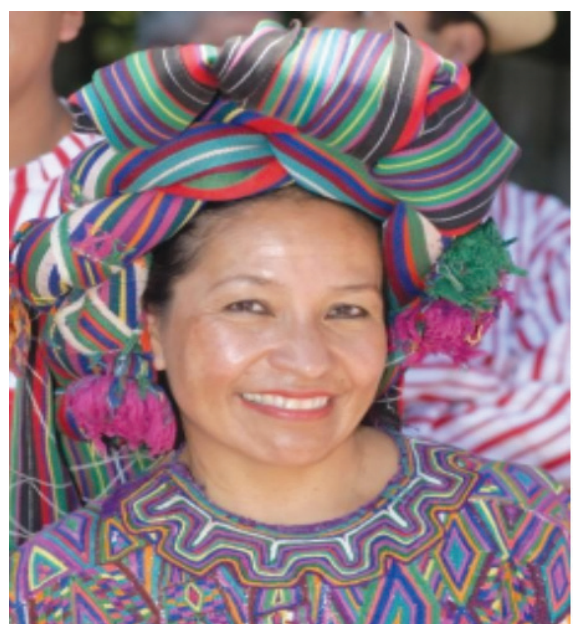

Fuente: Colección Lucía Armas

Fotografía 30.

Gira a España, 1999.

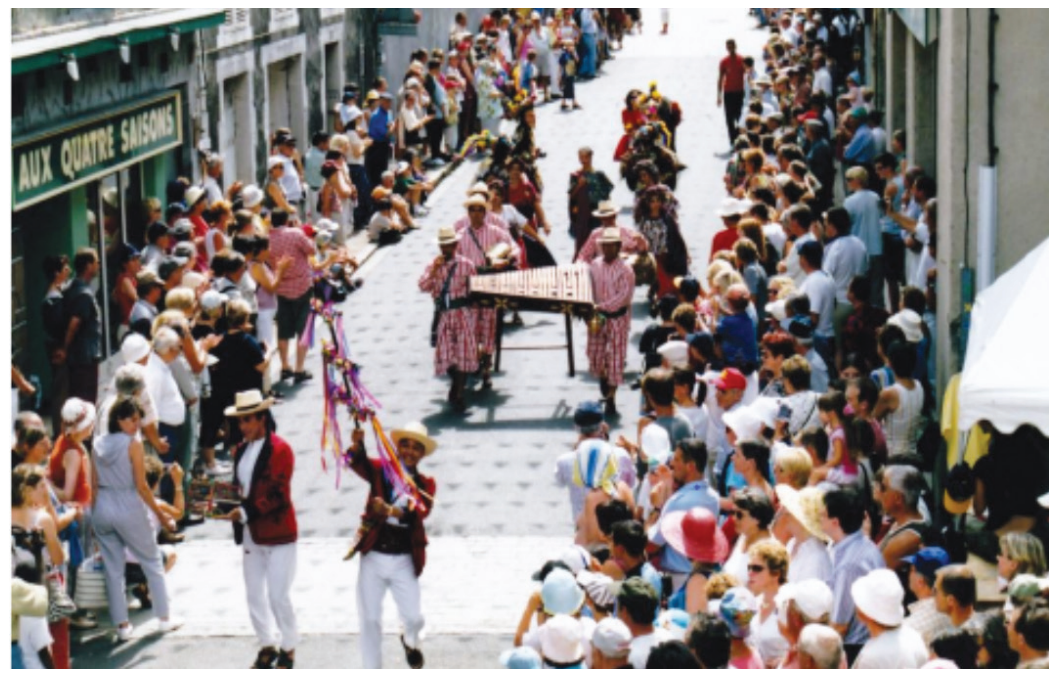

Fuente: Colección Iván Solís

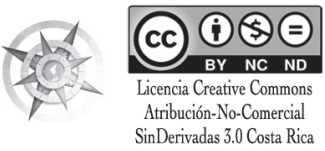




\section{Ballet del Inguat}

Este es un proyecto realizado por la arquitecta y coreógrafa Julia Vela, fue presentado el 4 de febrero de 1988 a Zúñiga, directora de Inguat y la idea es aceptada; le sucedió en el cargo el arquitecto Julio Fonseca, que la llama para ponerlo en marcha en 1990. "De allí nace un nuevo grupo de danza, el Ballet Folclórico del Instituto Guatemalteco de Turismo" (Solórzano., 2017).
La ley orgánica de la institución señala lo siguiente: "Son funciones específicas del Inguat para promover el turismo receptivo ofrecer en lugares adecuados representaciones de bailes folclóricos y danzas con la mayor prioridad posible para lo cual el Inguat debe preocuparse por integrar los conjuntos que sean necesarios" (Mertins, 2012.)

\section{Fotografía 31.}

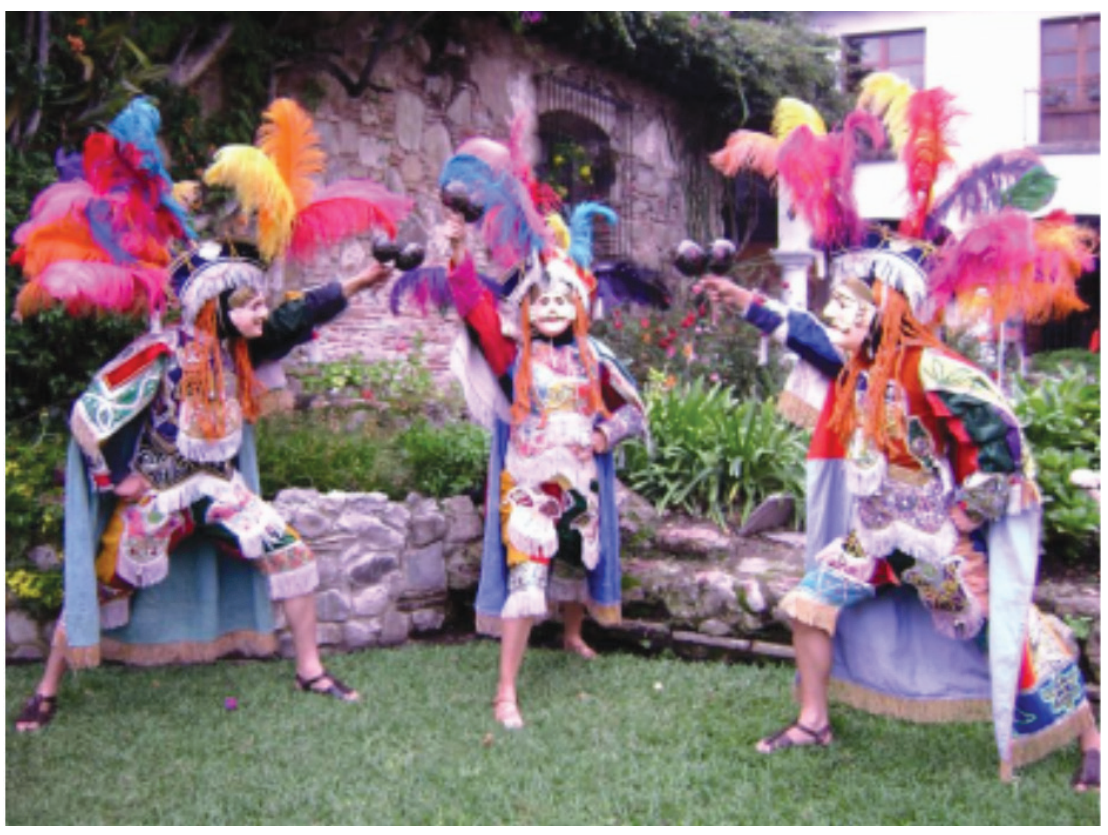

Fuente: Colección Ballet del Inguat

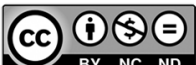




\section{Escuela Municipal de Danza}

Este es un proyecto que desarrolló la maestra Reyna Silva, exbailarina del Ballet Guatemala y exmaestra de la Escuela Nacional de Danza, ella tuvo la oportunidad de conocer el método del maestro Tulio de la Rosa (mexicano), quien desarrolló un método de enseñanza de la danza clásica para niños con condiciones físicas especiales. Cuando la maestra Silva regresó de México quiso, implantar el método en la Escuela Nacional de Danza, pero "hubo celos, obstáculos y falta de profesionalismo de parte de la dirección de la Escuela $\mathrm{Na}$ cional de Danza” (Mertins, 2012).

La carrera tiene una duración de diez años y nació en el 2004, lograron en el año 2007, a través de un acuerdo ministerial, la aprobación del Bachillerato en Arte Especializado en Danza Clásica (Acuerdo Ministerial 321-2007) (Mertins, 2012).

\section{Grupo de danza de la Universidad de San Carlos de Guatemala danza USAC}

En el año 1991 un grupo de padres de estudiantes de la Escuela Nacional de Danza Marcelle Bonge de Devaux hacen gestiones para formar un grupo de danza que perteneciera a la Universidad de San Carlos de Guatemala (Mertins,
2012, pág. 67).

El objetivo era crear un espacio de trabajo artístico diferente a las existentes instituciones del Estado y las privadas. Además, esto abriría la posibilidad de crear un grupo de danza a nivel superior. Este proyecto se presentó a la Dirección de Extensión Universitaria a cargo en ese entonces del Dr. Manuel González Ávila, quien dio los primeros pasos para que se formara una comisión de proyecto para realizar gestiones con el fin de lograr financiamiento (Mertins, 2012).

\section{Escuela Nacional de Danza "Marcelle Bonge de Devaux"}

Inició sus labores el 2 de septiembre de 1949, con la finalidad de preparar a bailarines y bailarinas que posteriormente formarían las filas del elenco del Ballet Guatemala. En sus inicios fue dirigida por los esposos Katchourowsky y Tchernova.

Fue hasta en marzo de 1990 que la Escuela Nacional de Danza pasó a llamarse Escuela Nacional de Danza "Marcelle Bonge de Devaux", en honor a la maesra belga, quien fuera la primera en impartir clases una vez institucionalizada la danza en Guatemala. 


\section{Fotografía 32.}

Escuela Nacional de Danza, 1985.

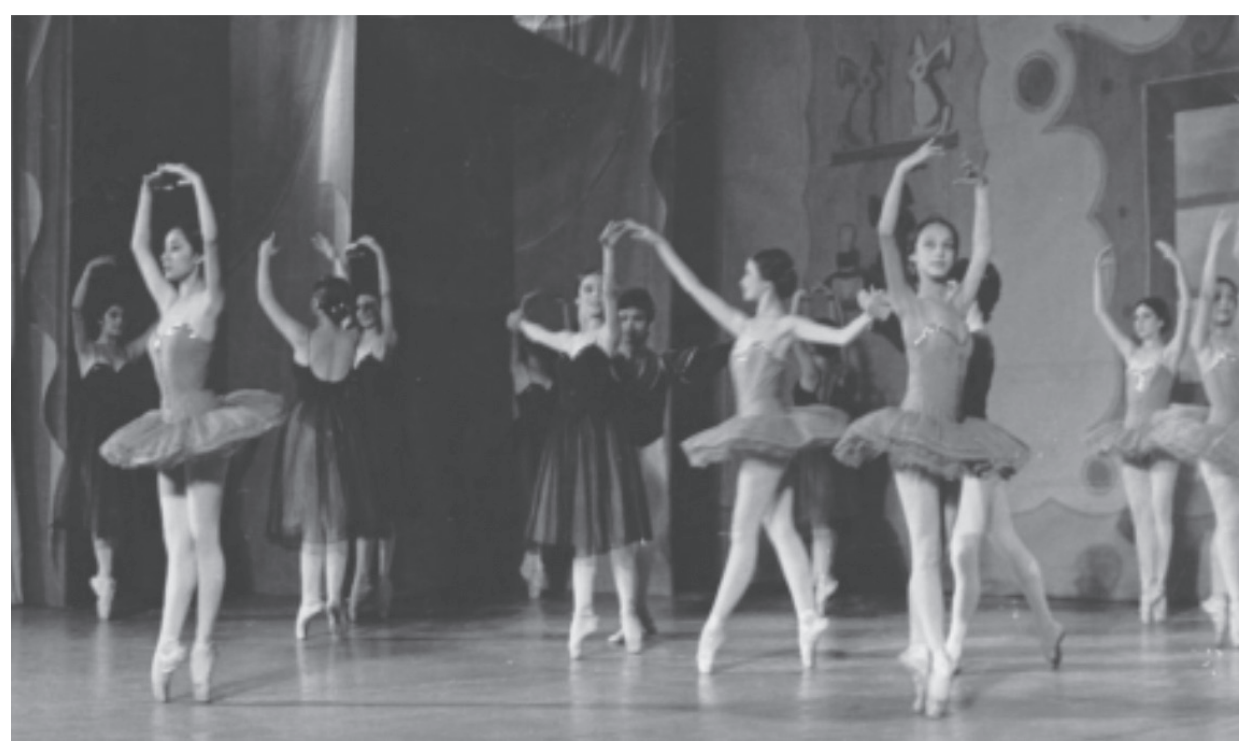

Fuente: Colección Karla Dardón 


\section{Academias y Grupos Independientes}

\section{Área Metropolitana}

A continuación, una pequeña recopilación de grupos y entidades independientes que forman parte importante de la danza en Guatemala actualmente.

\begin{tabular}{|c|c|}
\hline Momentum & $\begin{array}{l}\text { - Institución privada de la Universidad Rafael Landívar, } \\
\text { dedicada a la investigación de movimiento y creación de } \\
\text { danza contemporánea } \\
\text { - Fundación en } 1988 \\
\text { - } \text { Directora general y artística: Sabrina Castillo Gallusser } \\
\text { - Asistente de dirección: Dulce Paniagua } \\
\text { - Bailarines: } \\
\text { Andrea Ayala } \\
\text { Jeffrey Ortega } \\
\text { Sofía Barrios } \\
\text { - Brayan Córdova }\end{array}$ \\
\hline IQ MOON & $\begin{array}{l}\text { - Grupo independiente dedicado a producción artística y } \\
\text { - } \text { espectáculos de circo y danza contemporánea } \\
\text { - } \text { Bailarines actuales: } \\
\text { - Loyda Prado } \\
\text { - Amabilia Tejeda } \\
\text { - Yoseff Rivas }\end{array}$ \\
\hline Chevah & $\begin{array}{l}\text { - Compañía de danza contemporánea dedicada a montajes } \\
\text { - } \text { coreográficos y gestión artística } \\
\text { - } \text { Directora: Tania Morales } \\
\text { - Subdirector: Brayan Córdova }\end{array}$ \\
\hline Héroes & $\begin{array}{l}\text { - Academia privada dedicada a la producción de } \\
\text { espectáculos y enseñanza de estilos de danzas urbanas } \\
\text { - } \quad \text { Fundada en } 2014 \\
\text { - Director: Christian Ruano }\end{array}$ \\
\hline
\end{tabular}




\begin{tabular}{|c|c|}
\hline Fuga & $\begin{array}{l}\text { - Grupo independiente de danza moderna y contemporánea } \\
\text { - Directora: Adriana María Valdez Dardón }\end{array}$ \\
\hline Unidanza & $\begin{array}{l}\text { - Academia privada de danza con método "Royal Ballet" } \\
\text { - Directora: Betina Krebs }\end{array}$ \\
\hline $\begin{array}{l}\text { Escuela } \\
\text { Armonía }\end{array}$ & $\begin{array}{l}\text { - Escuela privada de danza con método "Royal Ballet" } \\
\text { - Directora: Virginia Gordillo }\end{array}$ \\
\hline $\begin{array}{l}\text { Estudio } \\
\text { Lizette } \\
\text { Mertins }\end{array}$ & $\begin{array}{l}\text { - Academia privada dedicada a la producción de } \\
\text { montajes artísticos y enseñanza de Ballet, Moderno y } \\
\text { Contemporáneo } \\
\text { - Directora: Lizette Metins } \\
\text { - Fundada en } 1984\end{array}$ \\
\hline $\begin{array}{l}\text { Antonio } \\
\text { Luissi }\end{array}$ & $\begin{array}{l}\text { Estudio privado dedicado a la enseñanza del Ballet, } \\
\text { acondicionamiento y danza contemporánea } \\
\text { - Director y fundador: Antonio Luissi }\end{array}$ \\
\hline Scenic & $\begin{array}{l}\text { - Academia privada dedicada a producción de montajes } \\
\text { artísticos, shows y clases de tap, hip hop y flamenco } \\
\text { - Fundada en el año } 2000 \\
\text { - Fundadora: Alice Flores de Barillas }\end{array}$ \\
\hline Unlimited & $\begin{array}{l}\text { - Academia privada dedicada a competencias, enseñanza de } \\
\text { Ballet, Contemporáneo y Jazz }\end{array}$ \\
\hline $\begin{array}{l}\text { Perfect Danza } \\
\text { Academy }\end{array}$ & $\begin{array}{l}\text { - Academia privada dedicada a la enseñanza de Ballet, Jazz y } \\
\text { Danza Contemporánea } \\
\text { - Fundadora y directora: Thelma Aguilar } \\
\text { - Año de fundación: } 2005\end{array}$ \\
\hline $\begin{array}{l}\text { Split Dance } \\
\text { Studio }\end{array}$ & $\begin{array}{l}\text { - Academia privada dedicada a la enseñanza de Ballet y Jazz } \\
\text { - Directora y fundadora: Waleska Ramírez } \\
\text { - Año de fundación: } 2003\end{array}$ \\
\hline Rios Dance & $\begin{array}{l}\text { - Academia privada dedicada a entrenamiento, enseñanza y } \\
\text { competencias de danza contemporánea, ballet y jazz }\end{array}$ \\
\hline $\begin{array}{l}\text { Estudio } \\
\text { de Danza } \\
\text { Lissette } \\
\text { Aguilar }\end{array}$ & $\begin{array}{l}\text { - Estudio privado dedicado al entrenamiento y enseñanza de } \\
\text { Danza Clásica Ballet, Contemporáneo y Jazz } \\
\text { - Fundadora y directora: exbailarina del Ballet Guatemala }\end{array}$ \\
\hline
\end{tabular}


Las antes mencionadas academias y grupos de danza se enfocan en prácticas como jazz, ballet, hiphop, contemporáneo, bailes latinos e incluso entrenamiento físico, entre otras técnicas de danza en el mundo moderno. Dedicadas a promover el arte en el área metropolitana de Guatemala.

\section{Interior del país}

Existen algunos otros grupos dentro del interior del país que se enfocan en cultivar y proteger las danzas tradicionales de sus pueblos, entre ellos puede mencionarse:

\begin{tabular}{|c|c|}
\hline Grupo Sotz'il & $\begin{array}{l}\text { - Entidad privada dedicada a la recuperación de } \\
\text { raíces culturales a través de la investigación y del } \\
\text { fomento de la música y danza prehispánicas mayas. } \\
\text { - } \text { Originarios del Tablón, Sololá, Guatemala } \\
\text { - } \quad \text { Fundado en el } 2000 \\
\text { - } \quad \text { Daniel Guarcax / coordinador del Grupo Sotz'il - } \\
\text { Tel: +502 } 51645109 \\
\text { - César Guarcax / subcoordinador del Grupo Sotz’il - } \\
\text { - Tel: +502 } 56333686 \\
\text { Luís Cúmes / Gestor - Tel: +502 } 59432118\end{array}$ \\
\hline $\begin{array}{l}\text { Danza Maya Jun } \\
\text { Chowen }\end{array}$ & $\begin{array}{l}\text { - Grupo integrado por personas originarias del } \\
\text { municipio de La Esperanza, Quetzaltenango; } \\
\text { dedicado a investigar, diseñar y presentar danzas } \\
\text { folclóricas para fortalecer y divulgar su cultura } \\
\text { - } \quad \text { Fundado en el año } 2000 \\
\text { - }\end{array}$ \\
\hline $\begin{array}{l}\text { Pelota Maya } \\
\text { Huahuetenango }\end{array}$ & $\begin{array}{l}\text { - Grupo independiente dedicado a presentar de } \\
\text { forma dancística y teatral el Juego Ancestral de } \\
\text { Pelota Maya -CHAAJ-con la finalidad de dar a } \\
\text { conocer las raíces de la cultura maya } \\
\text { - Pertenecientes a San Sebastián, Huehuetenango }\end{array}$ \\
\hline
\end{tabular}


Estos son grupos que existen en las comunidades del interior. Antropológicamente, se ha investigado que en cada municipio y comunidad hay uno o más grupos dedicados a realizar actividades de tradición en sus fiestas patronales, como danzas, juegos, rituales, música, entre otras actividades.

\section{Opiniones y entrevistas}

Varias generaciones de bailarines han pasado desde el primer grupo de danza teatral en Guatemala. El ballet clásico, las danzas de proyección folclórica e incluso la danza moderna y la contemporánea han sufrido cambios a través del tiempo. Tenemos opiniones de diferentes personajes importantes dentro de esta rama artística, la danza.

\section{Eddy Vielman (bailarín y maestro).}

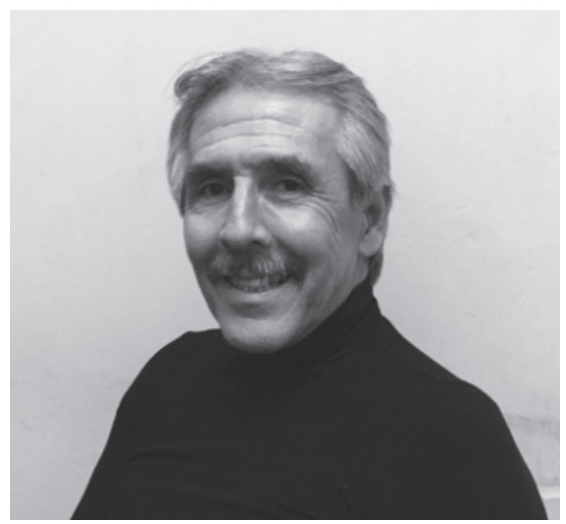

¿En qué año comenzó usted en la danza y cómo estaba la danza clásica en Guatemala en ese entonces?

Yo empecé en 1975 en la danza, tenía catorce años, en ese entonces los únicos que se dedicaban era el Ballet Nacional de Guatemala y el Ballet Moderno y Folclórico. No recuerdo otros grupos.

¿Qué opina de las danzas en Guatemala actualmente? ¿Cree que hay creaciones nuevas?

Actualmente hay muchas personas y grupos que se dedican a ello, tiene un lado positivo y es que la enseñanza ha tenido un efecto multiplicador. Pero hay otro aspecto no tan bueno, y es que ahora muchos de ellos no completan su preparación académica en danza, entonces hay muchos improvisados haciendo trabajos mediocres y así desvirtúan a los verdaderos bailarines, verdaderos coreógrafos, académicos y ya no digamos a los maestros. 


\section{Ileana Flores}

(bailarina y coreógrafa)

Danza del Paabank, Culul Ula, 2016. Ileana Flores.

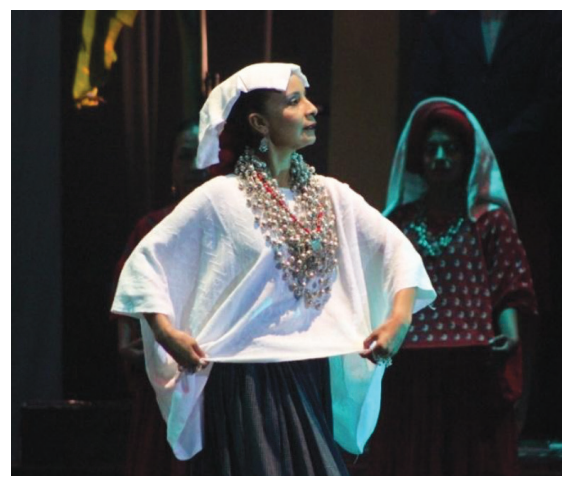

Fuente: Colección Neto Paiz

¿En qué año comenzó usted en la danza y cómo estaba la danza folclórica en Guatemala en ese entonces?

Me incorporé al Ballet Moderno y Folclórico en el año 1992, en ese momento no había muchos grupos definidos y conocidos en ese tiempo, solo el ballet y el grupo de Zoed Toledo, en el interior casi nada, coreógrafos de proyección muy pocos. Con el paso del tiempo han ido surgiendo más grupos, en el interior empezaron a aparecer pequeños grupos, digo a aparecer porque empezaron a presentar fuera de sus comunidades, dentro de ellas solo para sus fiestas patronales. Con el paso del tiempo han ido surgiendo más grupos, luego nació el Ballet del Inguat; en el interior empezaron a aparecer pequeños grupos

¿Maestra, usted qué opina de las danzas de proyección folclórica en la capital actualmente? ¿Cree que hay creaciones nuevas?

Mi percepción es que ha crecido la cantidad de los grupos que se dedican a la presentación de coreografías de proyección. Lo que veo es que generalmente hay poca investigación para la realización de coreografías. He observado que son los mismos temas que se escogen dentro de los grupos, no importa si son independientes o no.

En algunas ocasiones son hasta los mismos pasos, solo cambian un poco la estructura. También existen nuevas propuestas, pero creo que son muy pocas para la cantidad de grupos que existen. Creo que nosotros (los coreógrafos) tenemos un poco de culpa, por como acostumbramos al público. La gente no está acostumbrada a recibir nuevas propuestas y piensan que lo que les damos es lo único que hay. Pienso que dentro de estos grupos hacer folclor significa solo crear danzas tradicionales indigenas, y olvidan las demás culturas que existen en Guatemala.

Me pasó cuando presenté la recopilación de danzas peteneras, la gente 
lo asocia con la cultura mexicana o cuando presenté mi propuesta sobre Oriente, no lo querían presentar porque decían que no era representativo guatemalteco.

¿Porqué al ser algo nuevo, y tal vez poco conocido, lo asociaron con otra cultura?

Así es, pero recuerde que tenemos influencia de diferentes culturas. No lo ven así cuando es indígena, por los trajes, pero muchas danzas indígenas tienen otras influencias. Ejemplo: imagínese qué pensaría la gente si se presentara la danza de moros y cristianos sin el vestuario guatemalteco; ¿lo asociarían con Guatemala? Puesto que es una danza con origen español.

Con respecto a la cantidad de coreógrafos de folclore, le he de decir que hay muy pocos, creo que es una rama poco atractiva. Me refiero a gente que realmente investigue y lo traslade al escenario, no que escoja una música y le añada pasos. Lo que he visto últimamente en las comunidades del interior del país es que para renovarse o hacer algo diferente copian. Le voy a contar lo que me ocurrió a mí: para lograr poner en escena las danzas peteneras tuve que ir por casi tres años a Petén, o un poco más, fue un proceso de hacer amigos primero.
Y luego hicimos un intercambio con la dueña de unas danzas en Petén. Yo le enseñé cómo se hace la danza académica y ella me enseñó a bailar algunas de las danzas originarias, fue un proceso largo y entretenido. Al final de mi investigación, el montaje se presentó en el Ballet (Ballet Moderno y Folclórico de Guatemala, institución pública del Estado), algunos hechos folclóricos que no son danza, como Enhiladera de flores y la Alborada petenera son una visión muy propia de lo que observé. Esto fue hace tres años, el año pasado mi amiga, la que hice en los viajes de la investigación a Petén, me envió un video de un grupo de la comunidad con mi coreografía de Enhiladera de flores adaptada, y ahora ya son como dos grupos los que están presentando esta danza como folclórica petenera, lo malo es que fue una capitalina la creadora (risas). Pero también si alguien los ve, pensará que la que está copiando soy yo, pues no dan créditos (risas).

\section{¡Buena anécdota! Cuando llegue a Pe- tén voy a reconocer sus movimientos y diré que conozco a la creadora.}

Sí, mi amiga ya me pidió los derechos (risas). Si la hace literalmente sí, pero ellos hicieron una adaptación, le pusieron sal y pimienta, su toque especial (risas). En lo personal me asombra la cantidad de grupos que hay en esa región, creo que es consecuencia de un fuerte 
estímulo desde la escuela. He visto que son las maestras las que le han dado un gran impulso a la danza y la importancia a sus costumbres, aún sin siquiera que tomen una clase de danza.

Gracias por su tiempo y por la valiosa información.

Con gusto, ojalá crezcan las propuestas, sería bonito que tuviéramos mucho para elegir.

\section{Thelma Aguilar (bailarina y maestra)}

Thelma Aguilar en Kitry 1990. Fotografía por: Tito Arriola.

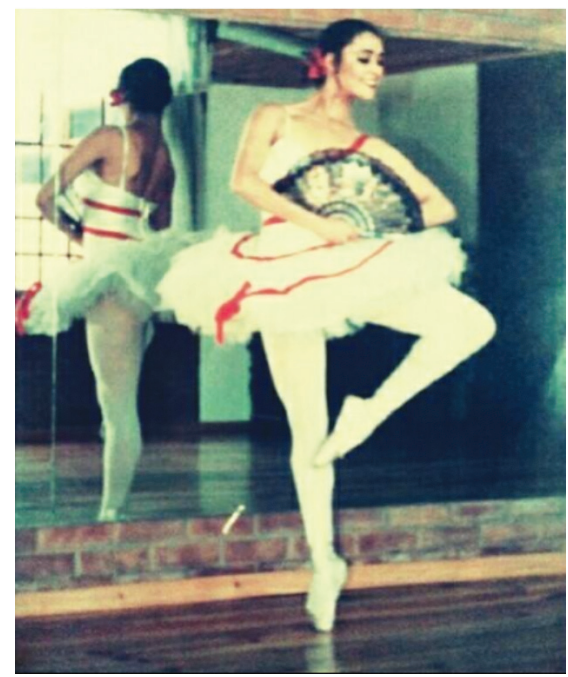

Fuente: Colección Thelma Aguilar
¿En qué año comenzó usted en la danza y como estaba la danza folclórica en Guatemala en ese entonces?

Yo entré a la Escuela Nacional de Danza en 1981, no conocía nada. Solo sabía que me gustaba por una monja del colegio donde yo estudiaba, porque me enseñó un poco y le habló a mí mamá.

Tengo buenos recuerdos de esa época, uno que estoy segura todos recordamos es que la Escuela era tipo militar, siempre bien portados y ese día Manuel Ocampo (director huésped en 1982) se fue, y jugamos tenta en el patio y gritamos un montón, no nos dejaba hablarles a los hombres y ese día jugamos todos. Yo estaba ya como en sexto grado. También viajábamos, con la Escuela solo fuimos a Honduras. Pero cuando estaba en la compañía del Ballet conocí toda Centroamérica y México. Recuerdo que una noche que veníamos de Honduras chocamos con un caballo (risas).

¿Conocía muchas academias o instituciones que dieran clases de Ballet?

Casi no había muchas como ahora. Sabía de Antonio Luissi, Coralea Penedo y Fabiola Perdomo. 
¿Cuál sería su opinión sobre cómo está el nivel de danza clásica en Guatemala actualmente?

Internacionalmente sí nos falta, pero sí hay mucha gente con talento, y prueba de ello son los que bailan en compañías extranjeras.

¿Cómo cree usted que puede solucionarse esta deficiencia que usted menciona, para estar mejor a nivel internacional?

Contratando maestros, capacitando a los que hay y evaluando a los alumnos, ya vez que así se ha logrado que los deportistas destaquen.

\section{Fernando Juárez}

(bailarín y actual director del Ballet Moderno y Folclórico)

Fernando Juárez, 2015. Gran Sala

Efraín Recinos del Teatro Nacional.

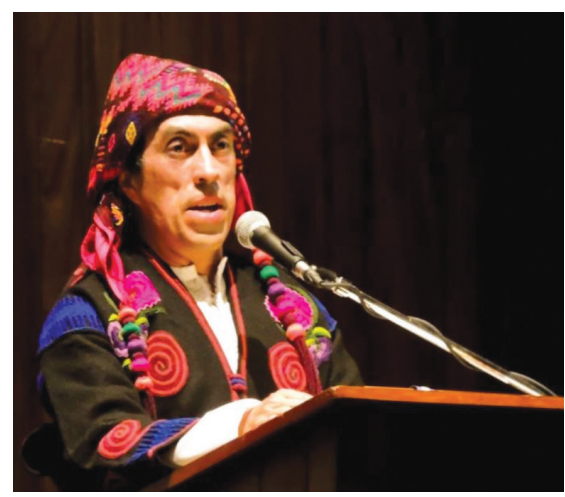

Fuente: Fotografía: Iván Martínez. Colección Fernando Juárez
¿Cuál es su opinión acerca de las danzas de proyección folclóricas actualmente?

Mi cargo actual es de director general del Ballet Moderno y Folclórico. Y en mi opinión no están protegidas las danzas folclóricas. Se tergiversa el folclor y lo manosean a su sabor y antojo. No le dan el respeto que se le debe, siendo nuestra identidad y se está perdiendo el sentimiento de las poblaciones de mantenerlas porque los jóvenes han perdido identidad.

Pienso que es urgente crear políticas sobre el tema, ya que tenemos una fortaleza a nivel mundial que está en el olvido. Esto es importante para nuestra integración como sociedad que evoluciona de forma desordenada. 


\section{Bran Solórzano \\ (exbailarín y coreógrafo)}

Foto 37. Bran Solórzano, México,2016. Autorretrato. Colección propia

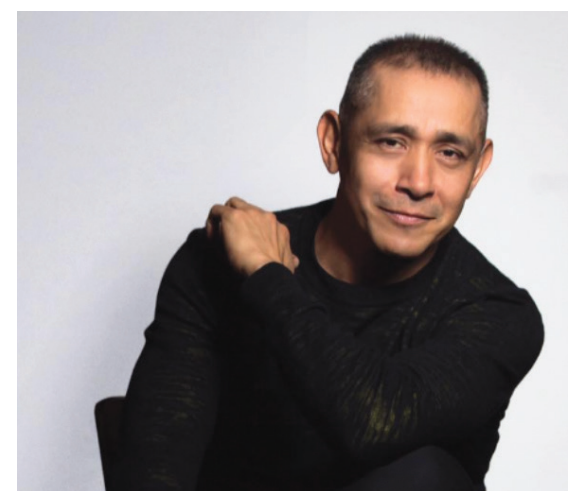

¿En qué año comenzó usted en la danza y cómo estaba la danza folclórica en Guatemala en ese entonces?

Inicié como en 1986 o 1987 en la compañía del Ballet clásico de Guatemala. Lo que recuerdo es que no había tantas academias privadas como ahora, en cuanto al ballet clásico había muy pocos bailarines hombres, por lo que se formó un grupo que llamaron experimental con jóvenes que se quisieran integrar.

¿Qué opina de las danzas de proyección folclóricas en la capital actualmente, cree que hay creaciones nuevas?

Tengo ya siete años de estar fuera de la danza en Guatemala, pero las veces que he visitado me ha impresionado mucho la cantidad de academias privadas y grupos independientes que existen actualmente, por lo que considero que sí ha estado en constante evolución, ahora en lo que a la danza de proyección folclórica se refiere creo que después de las creaciones de la arquitecta Julia Vela se ha estancado completamente, no he visto buenas propuestas. Quizá por ahí algunas de Ileana Flores y Amadeo Alvizures del Ballet Moderno y Folclórico, de ahí para adelante creo que han sido copias mal estructuradas y sin mucha investigación

\section{Conclusiones}

A partir de mi experiencia, me considero un resultado de todos mis maestros, que han sido formados por los grandes profesionales que alguna vez creyeron en la magia del arte del pueblo de Guatemala. Como estudiante y futura profesional, estoy dispuesta a seguir en la lucha; el artista y su oficio son un pilar importante para una sociedad justa, educada, ecuánime y próspera.

No hay que olvidar que Guatemala es una nación de postguerra que ha logrado ir reparándose de a pocos, y una de esas luchas constantes la hace el artista guatemalteco. Actualmente, la danza y el arte en Guatemala han evolucionado lentamente, puesto que existen muchos grupos encargados de esta actividad multiplicadora, pero no siempre reciben

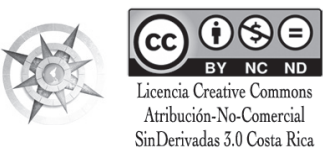


la ayuda ni atención necesarias. En nuestra sociedad la profesionalización del artista aún no es del todo aprobada por la academia y el pueblo.

Sin embargo, podemos ver cómo los artistas guatemaltecos siempre han luchado por un puesto respetable dentro de la academia, estudios superiores y profesionalización, por ello se ha fundado la Escuela Superior de Arte de la única estatal Universidad de San Carlos de Guatemala, con diez años de funcionamiento va sacando sus primeras promociones, dando así frutos positivos; pioneros y licenciados en arte. Entonces podemos decir que este es un tiempo de cambio para el arte en Guatemala.

Mi conclusión es que el arte y el conocimiento son la herramienta para educar a una mejor nación.

\section{Referencias bibliografías}

Armas, L. (2012). Ballet Moderno y Folclórico periodo 1992 - 2010 (L. Mertins, entrevistadora).

Castañeda, R. (2012). Ballet Guatemala. Galería Guatemala, p 24.

Cultura. (2008). Recuperado de httpp://cultura.muniguate.com/ index.php/section-blog/44-parquecolon/187-segundaparte
Devaux, R. (2017). Entrevista vía mensaje de texto. Recuperado de https://www.facebook.com/richardpaul.devauxbonge

El Periódico. (31 de enero de 2017). Quema de la Embajada de España. Recuperado de httpp://elperiodico. com.gt/opinion/2017/01/31/ quema-de-la-embajada-de-espana/

Elías, J. (2006). de Fernando Romeo Lucas García, expresidente de Guatemala. Recuperado de httpp://elpais. com/diario/2006/05/29/agenda/1148853605_850215.html

Flores, I (2017). Entrevista vía mensaje de texto. Recuperado de https:// www.facebook.com/Coguares

Hemeroteca Prensa Libre. (29 de diciembre de 2016). Gobierno y URNG firman la paz en 1996. Recuperado de httpp://www.prensalibre. com/hemeroteca/gobierno-y-urng-firman-la-paz-en-1996

Juárez, F. (2017). Entrevista vía mensaje de texto. Recuperado de https:// www.facebook.com/fernando. juarez.9212

Lima, E. (2009). Historias del Ballet Guatemala (L. Mertins, entrevistadora).

Mertins, L. (2009). 30 años de historia de la danza teatral, institucionalización cultural en Guatemala (1948-1978). Universidad de San Carlos de Guatemala. Recuperado de: httpp://digi.usac.edu.gt/bvirtual/ resumenes2009/inf0928.html 
. (2012). Danza Teatral en Guatemala 1978-2010. Dirección General de Investigación, Universidad de San Carlos de Guatemala. Recuperado de httpp://digi.usac.edu.gt/bvirtual/ informes/informes2012/INF. 2012-19.pdf

(2017). Entrevista videollamada Recuperado de https:// www.facebook.com/lizette.mertins

Museos Centroamericanos. (2012). Antecedentes históricos de la historia de Guatemala. Recuperado de httpp://web.archive.org/ web/20120214021306/httpp:// www.museoscentroamericanos. net:80/guatemala_museos/guatemala_historia.htm\#top

Ordóñez, R. F. (2008). Manifiesto Vértebra. Departamento de Educación Universidad Francisco Marroquín. Recuperado de httpp://educacion.ufm.edu/manifiesto-vertebra/

Paris, C. y Javier, B. (2011). Biografias. Recuperado de httpp://www. mcnbiografias.com/app-bio/ do/show?key=de-basil-coronel

Quiñónez, B. (2017) Entrevista vía mensaje de texto. Recuperado de https://www.facebook.com/ blancarosa.quinonezcastillo

Revista Galería Guatemala, (2014). Ballet Guatemala, Patrimonio Cultural de Guatemala Año 14, Número 41.p
Solórzano, B, (2017). Entrevista vía mensaje de texto. Recuperado de https://www.facebook.com/ bran.solorzano

Urrutia, C. (2011). Historia de Guatemala. Recuperado de https:// guatemaladeayer.blogs pot. com/2011/10/teatro-y-cine-capitol.html

Vielman, E, (2017). Entrevista vía mensaje de texto. Recuperado de https://www.facebook.com/eddy. vielman.3

Veliz, R. (2012). Conflicto armado en Guatemala. Sala de Redacción. Recuperado de httpp://saladeredaccion.com/revista/2011/10/ conflicto-armado-en-guatemala/ 